\title{
Preflame Zone Structure and Main Features of Fuel Conversion in Atmospheric Pressure Premixed Laminar Hydrocarbon Flames
}

Professor G.I. Ksandopulo

Combustion Problems Institute
RECEIVED

NOV 171995

OSTI

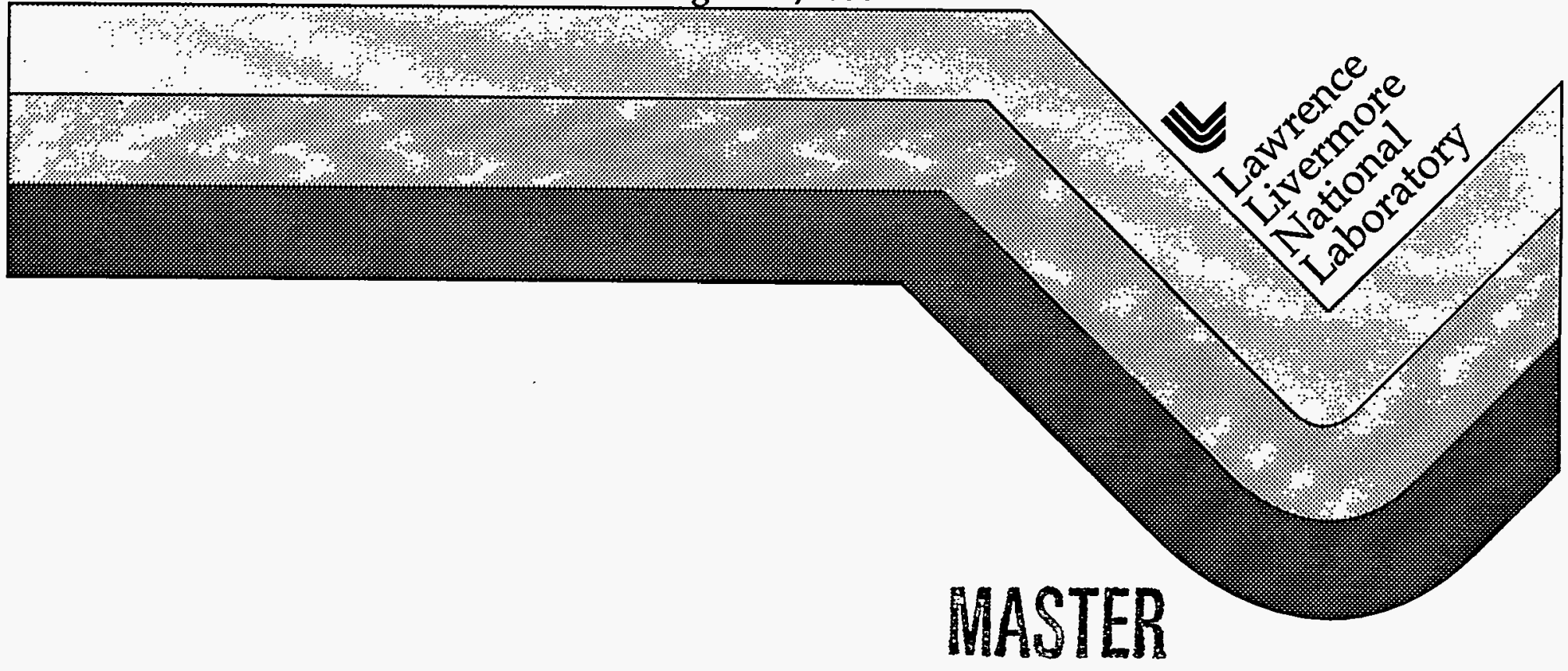

DISTFIBUTION OF THIS DOCUMENT IS UNLIMITED 
This document was prepared as an account of work sponsored by an agency of the United States Government. Neither the United States Government nor the University of California nor any of their employees, makes any warranty, express or implied, or assumes any legal liability or responsibility for the accuracy, completeness, or usefulness of any information, apparatus, product, or process disclosed, or represents that its use would not infringe privately owned rights. Reference herein to any specific commercial products, process, or service by trade name, trademark, manufacturer, or otherwise, does not necessarily constitute or imply its endorsement, recommendation, or favoring by the United States Government or the University of California. The views and opinions of authors expressed herein do not necessarily state or reflect those of the United States Government thereof, and shall not be used for advertising or product endorsement purposes.

Work performed under the auspices of the U.S. Department of Energy by Lawrence Livermore National Laboratory under Contract W-7405-Eng-48. 
MATERIAL SUPPORT AGREEMENT NO.B307951

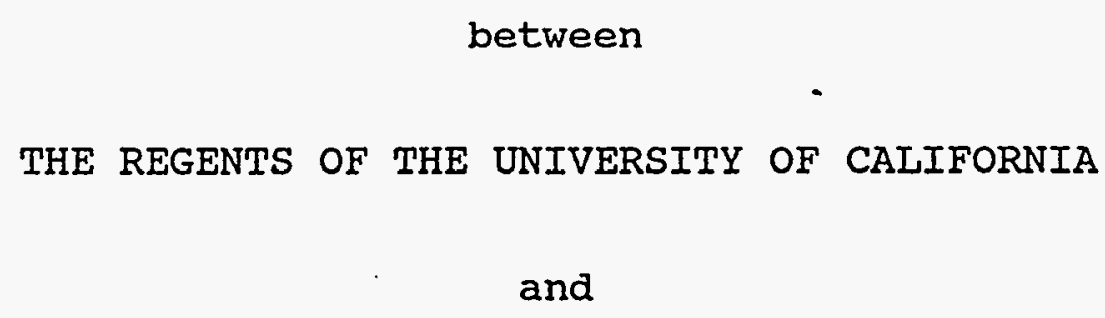

COMBUSTION PROBLEMS INSTITUTE

Title: FIAME FRONT STRUCTURE FOR PENTANE ISOMERS

REPORT NO.1. Title:

PREFLAME ZONE STRUCTURE AND MAIN FEATURES OF FUEL CONVERSION IN ATMOSPHERIC PRESSURE PREMIXED LAMINAR HYDROCARBON FLAMES

Lead Author: Prof. G.I.Ksandopulo

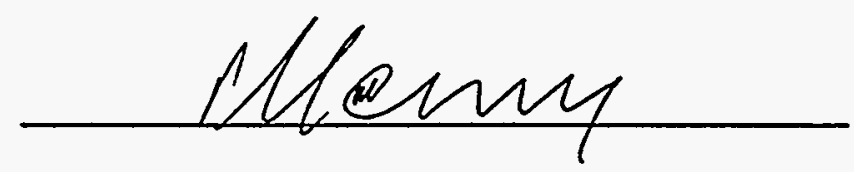

Date: Cugus, 25, 1995 


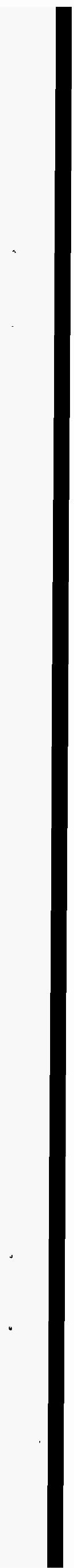


PREFLAME ZONE STRUCTURE AND MAIN FEATURES OF FUEL CONVERSION IN ATMOSPHERIC PRESSURE PREMIXED IAMINAR HYDROCARBON FLAMES

The present report describes the structure study of the premixed hydrocarbon-oxidizer Bunsen flames burning at the atmospheric pressure and also the ones with some inhibitors added. The choice of Bunsen flame as an object of investigation can be accounted by the interest to the phenomena of the hydrocarbons low-temperature oxidation close to the hot flame front. After several years of study we've come to a conclusion that the phenomenon of chain autocatalysis always exists in the hydrocarbons flames especially in those with a longer carbon chain.

Low-temperature reactions are stabilized in the diffusion field of the atomic hydrogen the source of which is the thermal auto-accelerated reaction zone (high-temperature zone). Negative temperature dependence of the fuel consumption rate as a characteristic feature of the total reaction, on the one hand, and strong initiation of the oxidation reaction in the incoming flow of fresh fuel mixture, on the other, confine this process to the low- temperature zone as a part of the hot flames front, as e.g. Bunsen flames and those like them. It is evident the flame having such a structure will be distorted at the flat flame burners due to the facilitated run-off of heat and active centers to the burner's matrix.

Conic flames lack such distortions though other problems are kept such as rigid conditions for the sampling and temperature measurement, reaction quenching, etc. These problems have been to some extent surmounted in the obtained results. Here is presented only a part of the materials on Bunsen flames probing during 1970-1990. It's described much more detailed in two monographs published in 1980-1986.

It is assumed in most of the known combustion theories that the reactions before the flame front boundary at the temperature that is lower than the combustion temperature may be neglected [1-3]. This assumption allowed to simplify the problem of analytical solution and to promote significantly thermotechnical calculations. However, flame model created on the basis of this 
assumption is considered by many of the investigators as physical reality, thus believing that reactions in the preflame zone can really be neglected. Nevertheless, for a long time there have been known a strong effect over flame propagation of little addition of some certain compounds introduction of which into a fresh combustible mixture doesn't change significantly thermophysical properties, thus contradicting to the assumption made. Zel'dovich introduced [3] restrictions of the thermal theory of combustion assuming that it can be applied to rather rare "non-chain" flames. At the same time regularities of the fuel conversion in the flame front with autocatalytic nature are not yet clear.

The preflame zone structure of hydrocarbon flames.

Experimental study of structure of the premixed Bunsen-like flames burning at atmospheric pressure has been conducted using microprobing technique of sampling and microthermocouples. Flame sampling has been done by means of non-cooled microprobe followed by mass-spectrometer analysis. The probe is a quartz tube, 5 to 10 mm i.a., with the pulled conic tip. The probes used have the orifice diameter $60-80 \mu \mathrm{m}$, and the angle 30 degrees. The probes were inserted into the flame cone without any evident perturbations in it. Microprobes are to provide minimal flame perturbation. In [4] adiabatic gas flow has been calculated in the area adjacent to the probe orifice and inside it. The results show that cooling due to the adiabatic gas expansion at a distance equal to the orifice diameter upstream decreases the temperature by $5 \%$, and just at the orifice of the probe by $20 \%$. Thus, the result of the analysis gives the composition of the gas corresponding to the point for unperturbed flame which is at a distance from the probe orifice approximately equal to its diameter. Thermal distortions in the flame structure arising during insertion of the microprobe are shown to be neglected [5]. Results obtained in the above works allow to assume that no visible distortions were observed in the luminous zone on inserting used microprobes, which was confirmed by schliren photography [6], at least at the distances larger-that the orifice diameter.

Let's consider the possibility of the reactions quenching. In the typical case of sampling gas expansion occurs up to several hundred times during a few microseconds [7]. In such a short 
period of time there can occur several thousand double collisions. After sampling not only pressure falls down but the temperature decreases down to the room temperature so that the reactions passing with the activation energy other than zero, will be quenched.

A commonly used probing technique is the one at which the probe is introduced from the hot side of the flame. However, during sampling from the preflame zone in that part of the probe which is locally heated by the flame hot zone there appears a possibility of undesirable reactions. Due to the estimation [5], heating up of the probe walls doesn't exceed 800K. The length of the heated zone is $0.2-0.3 \mathrm{~cm}$. Time period within which a chosen sample resides in that zone at usual volumetric rates of sampling does not exceed $0.001 \mathrm{~s}$, which is much less than the reaction times typical for these conditions. The chance of neglecting the reaction in the heated part of the probe is evidently proved experimentally $[6,7]$ : concentration profiles, measured at microprobe insertion from the hot side of the flame, were well reproduced during measurement as with the probe inserted from the cold side, when the probe heating was, of course, absent.

A range of perturbations, caused by sampling, was estimated by as theoretically [4].Fig.1 is a plot of the dependence of the distance $z$ measured by the number of the radia $r$ of the orifice between the orifice plane of the probe and the point where flow distortion decreases down to $5 \%\left(\mathrm{~V}_{\mathrm{y}} / \mathrm{V}_{\infty}=0.05\right)$ on the relative rate of sampling $\alpha$ :

$$
\alpha=\frac{Q}{\pi r^{2} \times V_{\infty}},
$$

where $Q$ - a volumetric flow velocity, $V_{\infty}$ - a nonpertubated velocity. For typical rates of sampling the value $\alpha$ is $10-100$, and 5\% flow distortion occurs at a distance of 5-10 orifice radia upstream. For the probe with the orifice radius equal to $15 \mu \mathrm{m}$ this distance constitutes $0.08-0.15 \mathrm{~mm}$ which is not a significant aerodynamic perturbation.

Temperature measurement in the front of the flames under study was carried out by thermocouples Pt-Pt/Rh (10\%) with the wire diameter20-30 mm. Wires were butt-weld under the microscope.To exclude catalytic effect the surface of the thermocouples was coated out by a thin layer of silica. The 


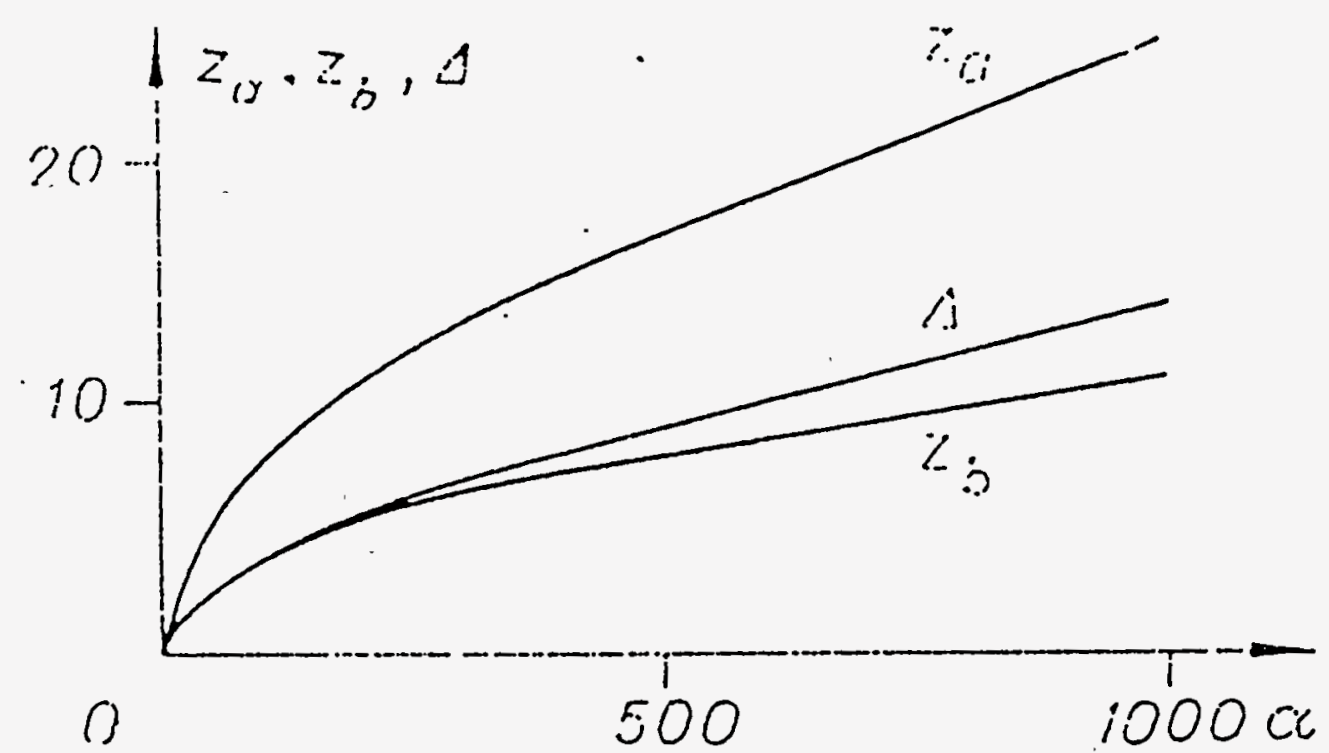

Fig. 1 Dependence of location and width of the sampling zone in the unperturbed flow on $\alpha$. 
thermocouples had G-form to exclude, errors due to the heat flow along the thermocouple wires. The length of the arm was calculated by the empiric formula [10]. It's not possible to take into account all of the errors of temperature measurement but a part of them can mutually compensate each other.

\section{Hexane Flame}

We've studied a rich hexane flame (the composition of the combustible mixture being: $c_{6} \mathrm{H}_{14}-8.5 \%, 0_{2}-28 \%$, Ar-63.5\% at different initial temperatures of this mixture - $344 \mathrm{~K}$ and $480 \mathrm{~K}$ [11]. Fig.2 gives the temperature profiles in the preflame zone and the temperature calculated by the Mikhelson's equation. In all the figures here and further the origin of the abscissa axis coincides with the cold boundary of the luminous zone the positive direction being chosen towards the after-burning zone. Conductive heating of the mixture is limited by the layer near the luminous zone, and warming up due to the reaction starts from the point $z=-2.4 \mathrm{~mm}$. Almost in the same point there was noted, the beginning of the hexane and oxygen consumption and formation of $\mathrm{CO}$ and $\mathrm{CO}_{2}$ (Fig.3). Hexane is consumed almost totally before reaching the luminous zone, and carbon oxides formation is accompanied by a relatively small heating up of the mixture.

For such relatively long-chain hydrocarbon as hexane, more explicit cold flame processes could have been expected in the preflame zone of hot flame compared to the propane flame earlier studied by us. As a criterion of the cold flame presence we've used negative temperature (NTC) dependence of the reaction rate. In fact, with the increase of the initial temperature of the combustible mixture, maxima of total rates of hexane disappearance is decreased (Fig.4), and reaction rate profiles of the other substance behave differently. Fig.5 gives the volumetric heat release rate profiles in the hexane flames under study. It is shown that there is a region before the luminous zone the heat release curve of which is similar to that of cold flames, i.e. the growing amplitude of heat release rate before the mixture reaches the hot flame phase. Besides, the dependence of the heat release rate peak before the flame front upon the initial temperature is observed due to the enhancement of the competing reaction of the $\mathrm{RO}_{2}$ radical disappearance as compared with the conventional cold flame channel as is described below. However, in the hexane flames 


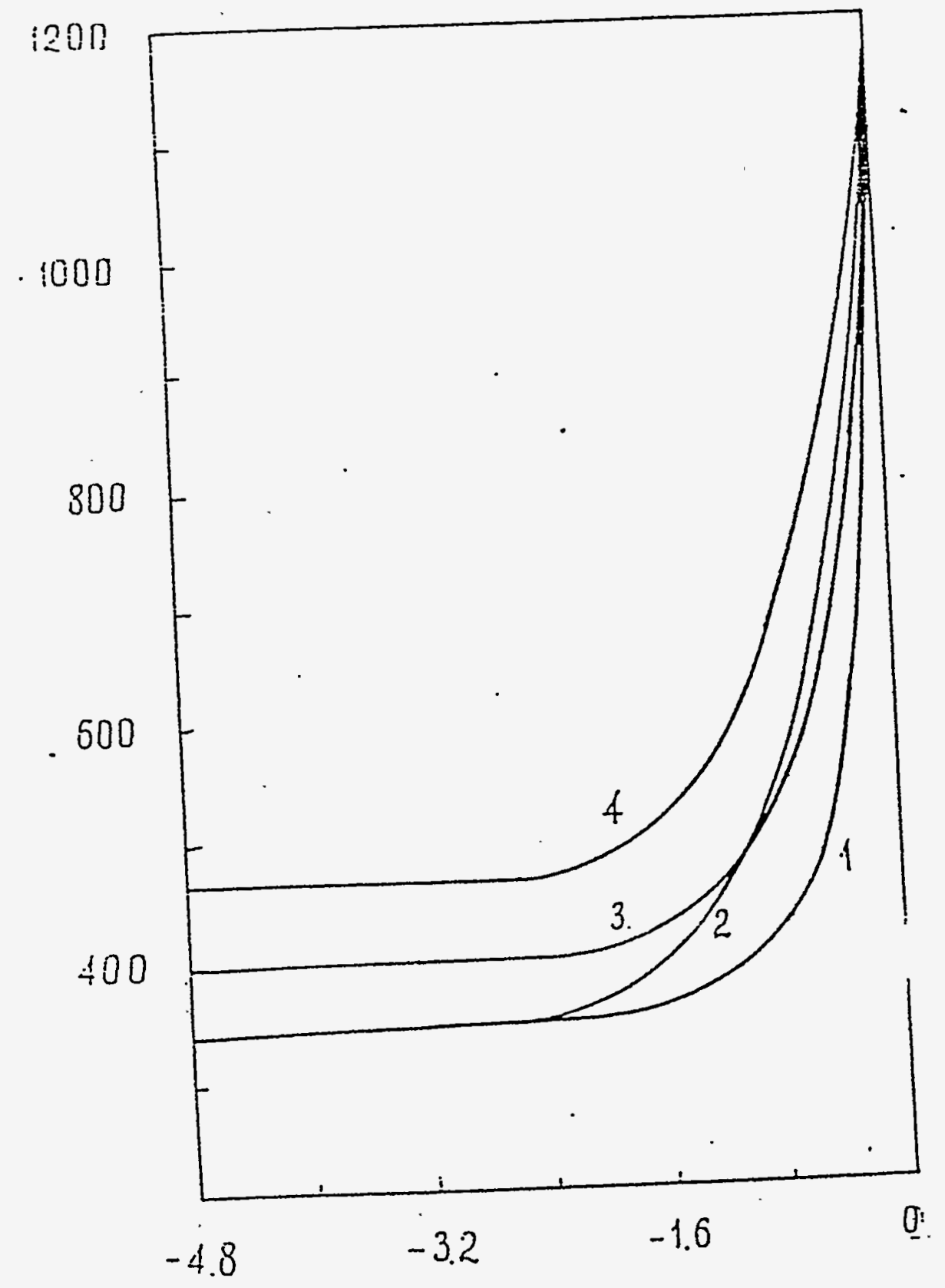

Fig.2. Temperature profiles for the rich hexane flame $\left(8.5 \% \mathrm{C}_{6} \mathrm{H}_{14}, 2.8 \% \mathrm{O}_{2}, 63.5 \% \mathrm{Ar}\right)$ with the different initial temperature. (1) calculated; (2) $\mathrm{T}_{0}=344 \mathrm{~K}$; (3) $\mathrm{T}_{\mathrm{O}}=404 \mathrm{~K}$; (4) $T_{0}=480 \mathrm{~K}$. 


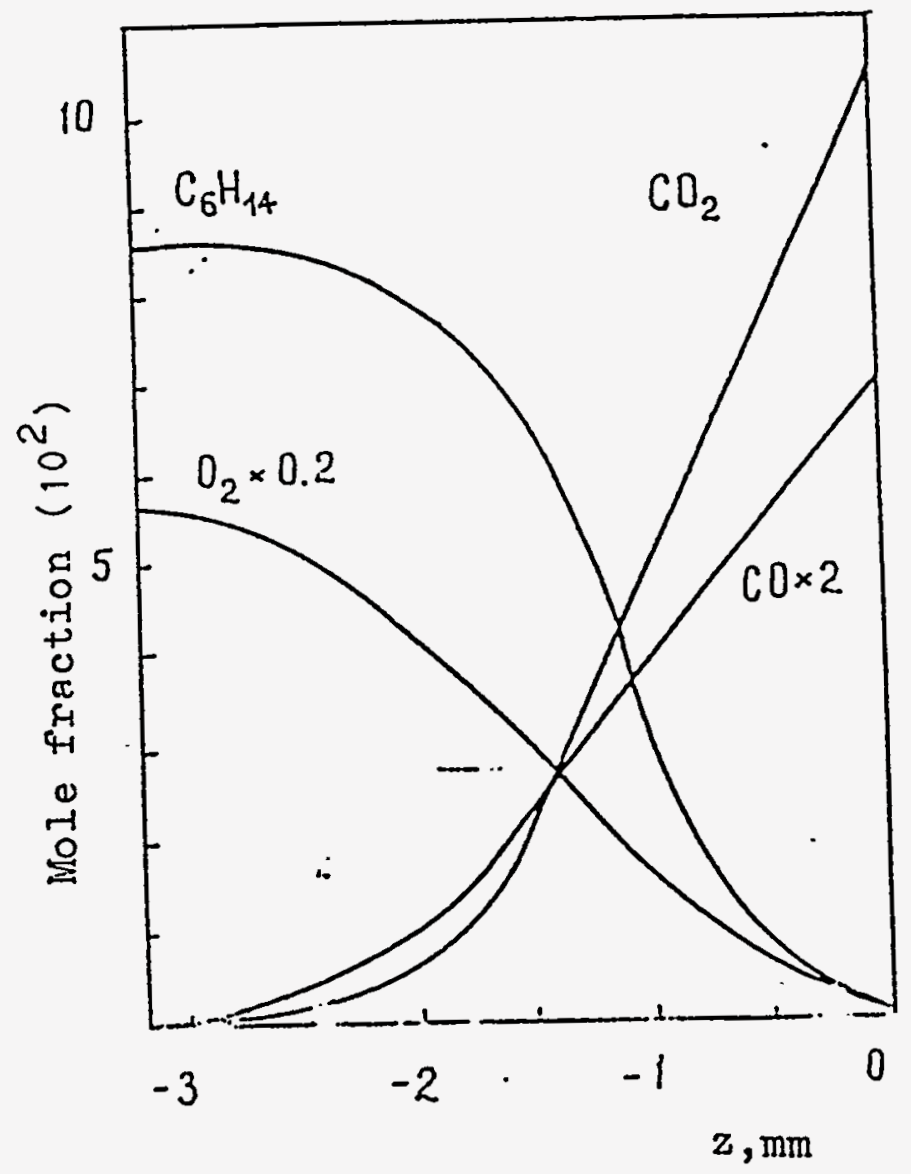

Fig.3. Concentration profiles for $\mathrm{C}_{6} \mathrm{H}_{14}, \mathrm{O}_{2}, \mathrm{CO}_{2}$ and $\mathrm{CO}$ in the hexane flame at $T_{0}=480 \mathrm{~K}$. 


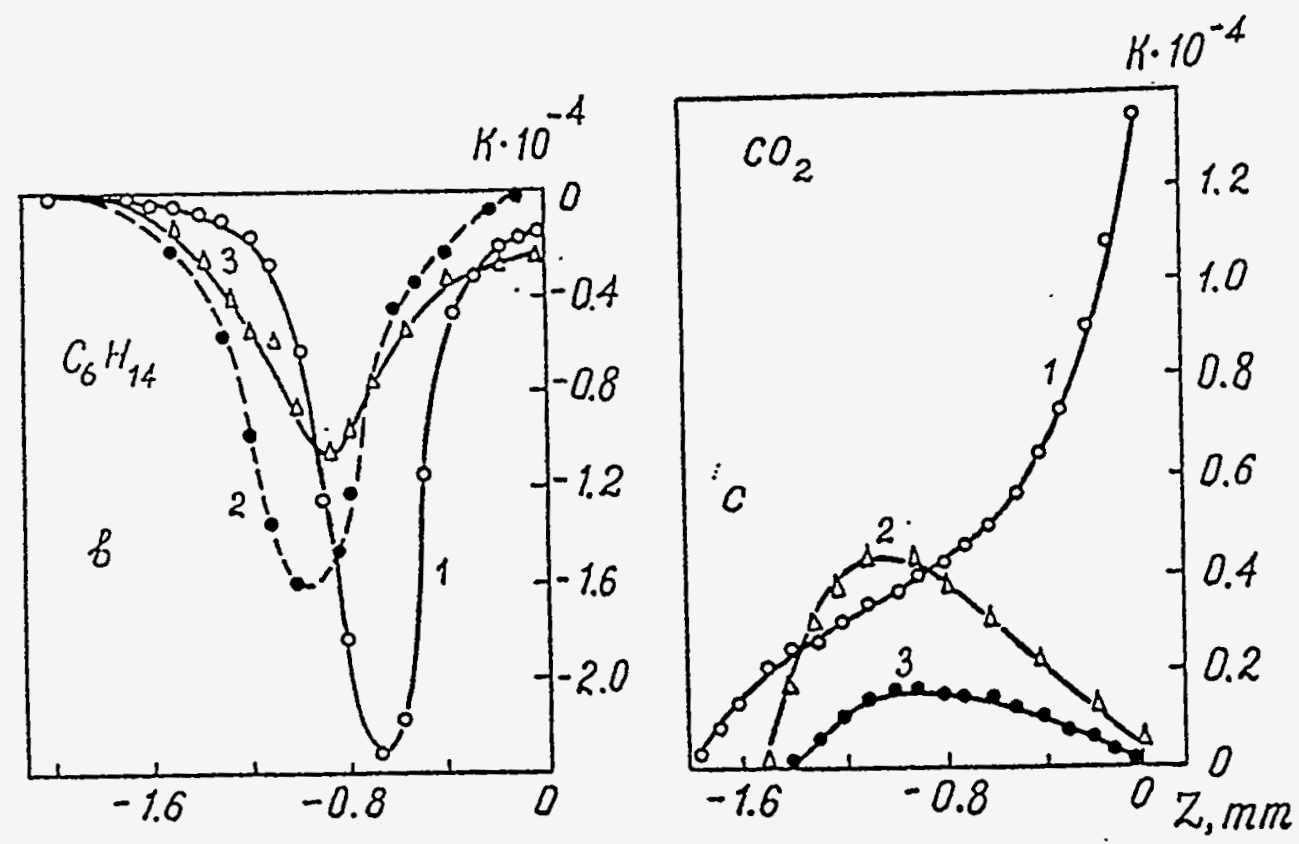

Fig.4. Negative temperature dependence of the consumption and the formation rate $(K)$ in the flame front $\left(\mathrm{C}_{6} \mathrm{H}_{14}-8.5 \%\right.$, $\left.\mathrm{O}_{2}-28 \%, \mathrm{Ar}-63.5 \%\right)$

I. $T_{0}=344 \mathrm{~K} ; \quad 2$. $T_{0}=404 \mathrm{~K} ; \quad 3 . T_{0}=480 \mathrm{~K}$ 
$\Phi\left(j \cdot \mathrm{cm}^{-3} \cdot \mathrm{s}^{-1}\right)$

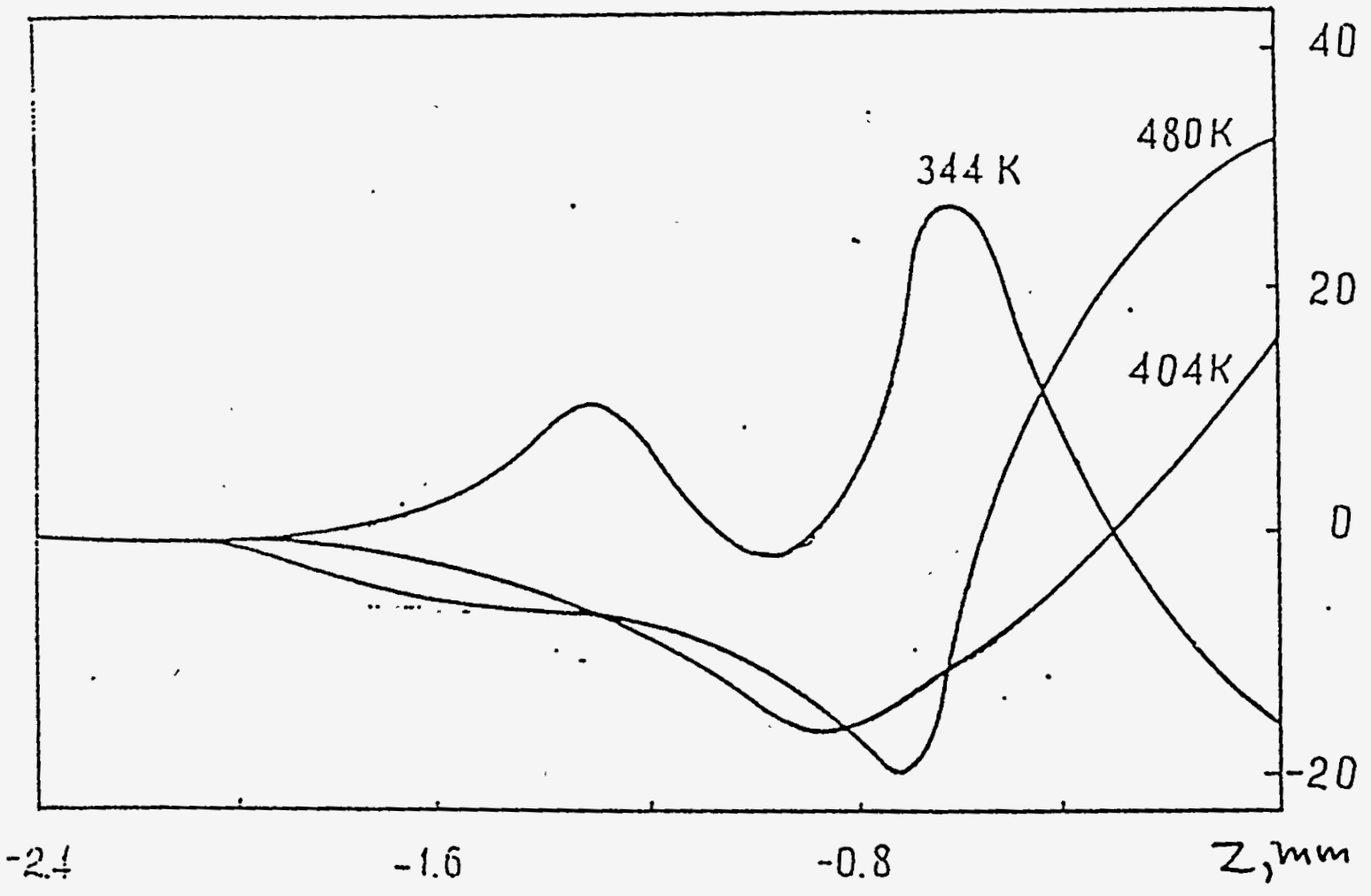

Fig.5. Heat release rate ( $\Phi)$ profiles in the hexane flame at the indicated initial temperatures. 
$\mathrm{H}_{2} \mathrm{O}, \mathrm{H}_{2}, \mathrm{C}_{2} \mathrm{H}_{4}, \mathrm{C}_{2} \mathrm{H}_{2}, \mathrm{CH}_{4}, \mathrm{CH}_{2} \mathrm{O}, \mathrm{C}_{3} \mathrm{H}_{8}, \mathrm{C}_{3} \mathrm{H}_{6}$, i.e. the products typical for cold flames were not detected. Therefore, the method of sample accumulation with the following freezing out was used to study the peroxide distribution in the preflame zone of the rich hexane-air (2.4\% of hexane) flame [12]. After the sample was frozen out it was analyzed by iodometry and polagraphy. Fig.6 shows the profile of the total peroxides concentration and the temperature profile in the preflame zone of the above flame. At point $z=-0.5 \mathrm{~mm}$ and at $T=380 \mathrm{~K}$ the total amount of peroxides reaches a significant amount $6 \times 10^{15} \mathrm{~cm}^{-3}$. Polarographic method allowed to show that peroxides composition in various points of preflame zone is different. At point $z=-2.1 \mathrm{~mm}$ only alkylperoxides are found, at $z=-1.0 \mathrm{~mm}$ appears hydrogen peroxide and then dialkylperoxides $(z=-0.5)$. Close to the luminous zone ( $z=-0.1 \mathrm{~mm})$ only hydrogen peroxide was detected.

In the course of study of the influence of the excess-fuel coefficient. value and the technique of the fuel supply upon the flame front structure there was studied a number of hexane-oxygenargon flames less rich in fuel $[13,14]$. Fig.7 represents the stable substance concentration and temperature profiles through whole reaction zone of the flames: $2.4 \% \mathrm{C}_{6} \mathrm{H}_{14} 16.4 \% \mathrm{O}_{2}, 81.2 \% \mathrm{Ar}$, and Fig. 8 - the balance by the elements $C, H, O$, calculated by the flux fractions. Average deviation from the balance is only $10-15 \%$. Probing at the distances more than $1.5-2.0 \mathrm{~mm}$ in the afterburning zone showed oxygen penetration from the environmental air into that zone to become noticeable. In the high-temperature zone there are found present mostly $\mathrm{CO}, \mathrm{H}_{2}, \mathrm{CO}_{2}, \mathrm{H}_{2} \mathrm{O}$ and in small amounts $\mathrm{CH}_{4}$ and $\mathrm{C}_{2} \mathrm{H}_{2}$. As far as the preflame zone is concerned, its width increases with the fuel excess growth.

Acetylene and Hexene Flames

Existence of the low-temperature reaction zone was also proved. by us in the atmospheric lean acetylene-air flames $(4,1 \%$ $\mathrm{C}_{2} \mathrm{H}_{2}$ and, $4.8 \% \mathrm{C}_{2} \mathrm{H}_{2}$ ) [15] and in stoichiometric hexene-oxygenargon flame [16]. If hexene flame appears to be similar to the hexane ones regarding the products composition and preflame zone structure, but the width of the first one is somewhat narrower, i.e. $1.5 \mathrm{~mm}$, then the acetylene flames have their own features. First, there is noted formation of the intermediary product - 


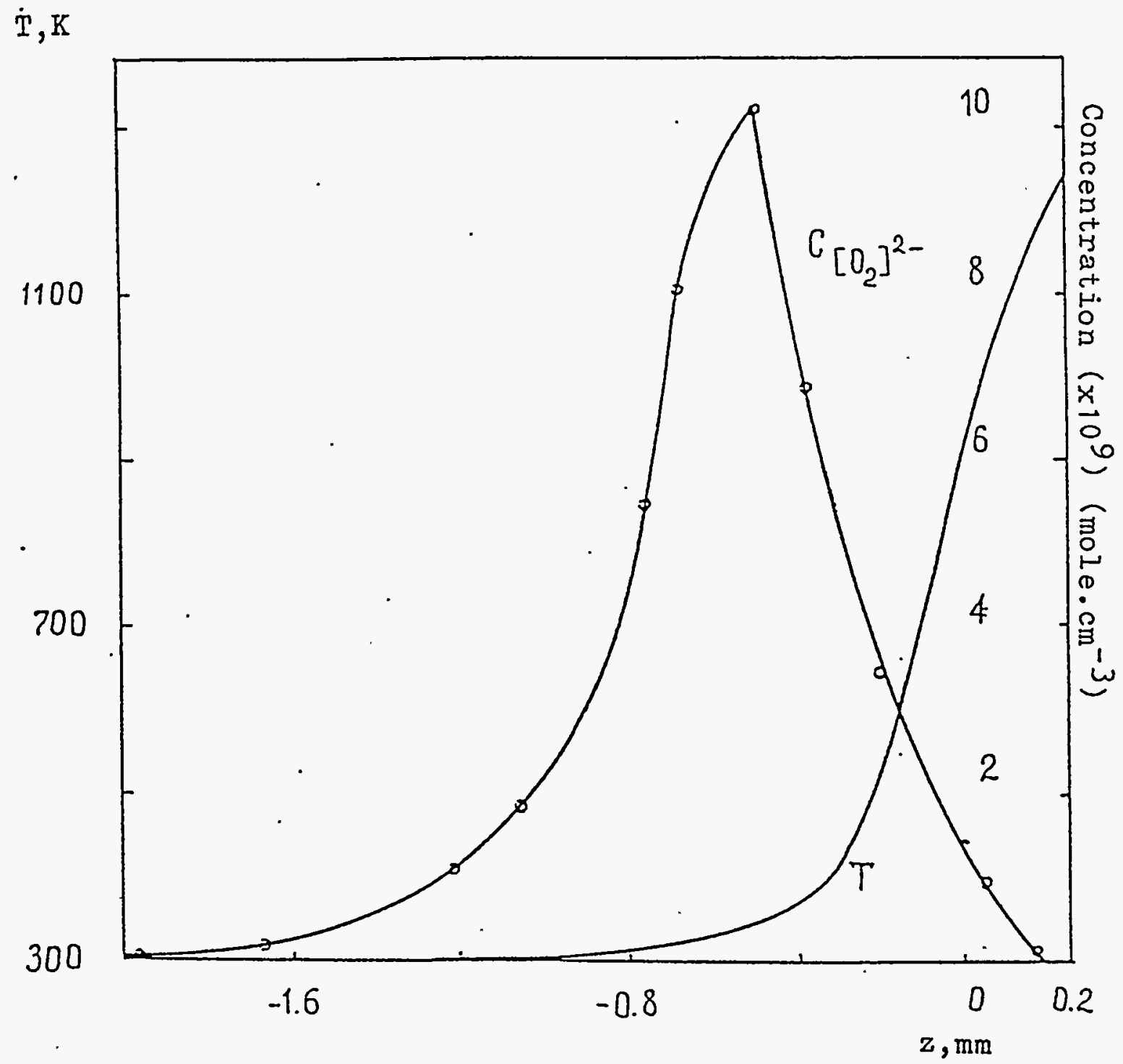

Fig.6. Total peroxide concentration profile and temperature profile in a rich hexane-air flame (2.47\% $\left.\mathrm{C}_{6} \mathrm{H}_{14}\right)^{\circ}$. 


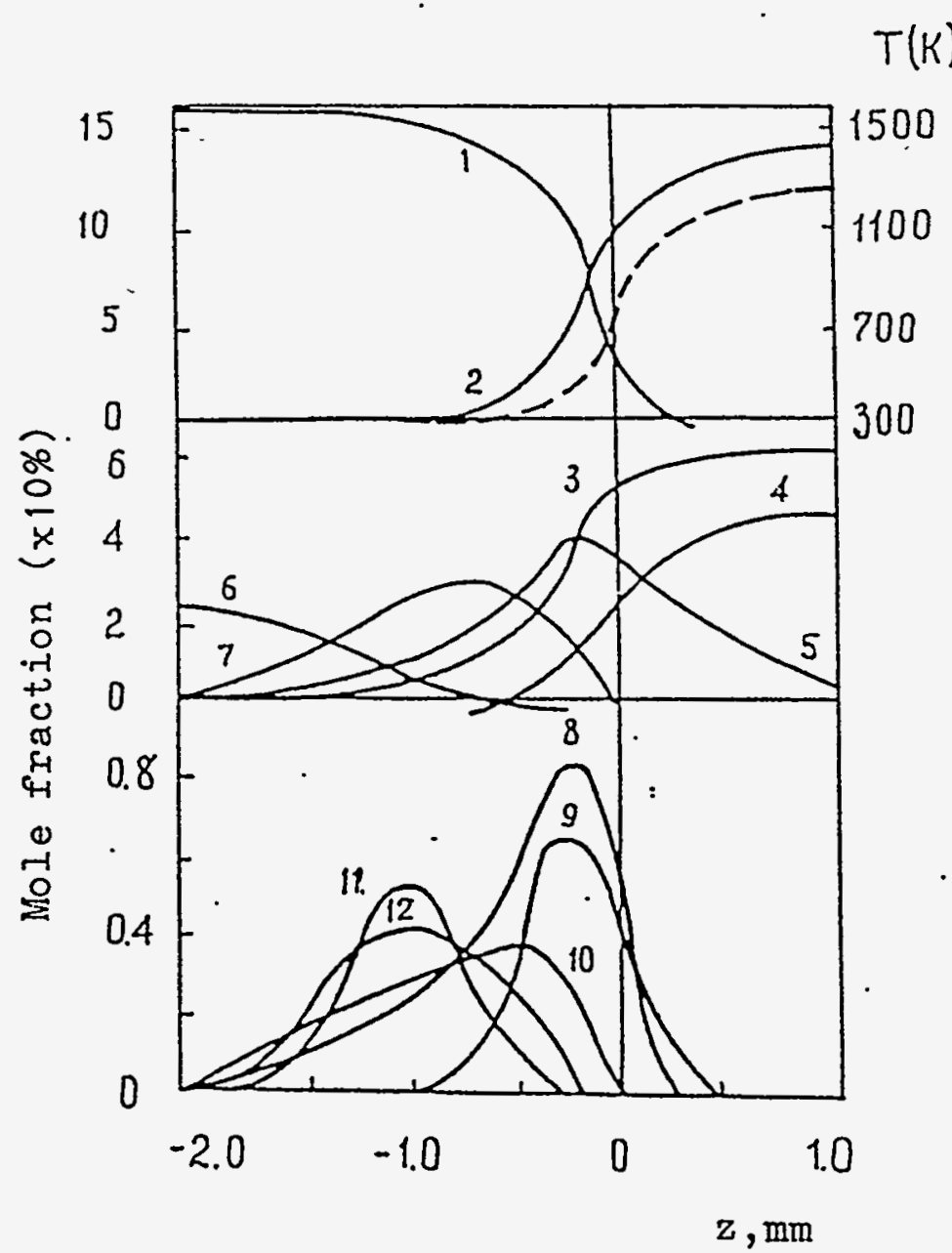

Fig.7. Temperature and concentration profiles for stable species in a rich hexane-oxygen-argon flame $\left(2.4 \% \mathrm{C}_{6} \mathrm{H}_{14}\right.$, $\left.16.4 \% \mathrm{O}_{2}, 81^{\circ} .2 \% \mathrm{Ar}\right) \cdot 1-\mathrm{O}_{2} ; 2-\mathrm{H}_{2} \mathrm{O} ; 3-\mathrm{CO}_{i} 4-\mathrm{CO}_{2}$; $5-\mathrm{H}_{2} ; 6-\mathrm{C}_{6} \mathrm{H}_{14} ; 7-\mathrm{C}_{2} \mathrm{H}_{4} ; 8-\mathrm{CH}_{4} ; 9-\mathrm{C}_{2} \mathrm{H}_{2} ; 10-\mathrm{HCHO}$; $11-\mathrm{C}_{3} \mathrm{H}_{8} ; 12-\mathrm{C}_{3} \mathrm{H}_{6} ;$ dashed line for temperature profile. 


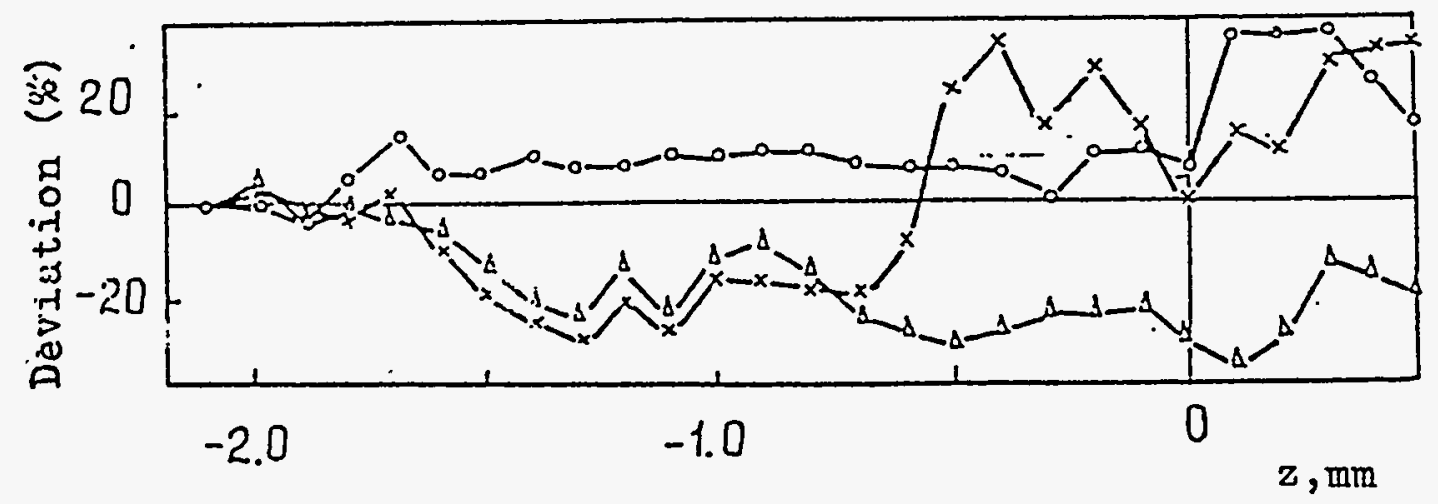

Fig.8. Conservation of elements $C, H$ and $O$ for the hexane flame. $\mathrm{O}-\mathrm{C}, \Delta-\mathrm{H}, \mathrm{x}-\mathrm{O}$. 
ethylene with the molecular mass that is larger than in the initial fuel-acetylene, which can evidently be accounted for by a greater level of the acetylene unsatuxation which leads to a more important role of the addition reactions. Second, though the beginning of the acetylene and oxygen disappearance with the simultaneous formation of the final and intermediate products is noted practically at the initial temperature of the combustible mixture, and acetylene is consumed totally close to the luminous zone then the temperature profile coincides with the calculated one supposing only conductive heating up (Fig.9). At the early stages of the acetylene conversion exothermal and endothermal effects seem to balance within the experimental error, but occurrence of the reactions in the preflame zone is undoubtful.

\section{Propane Flame}

Temperature and some species flux profiles in the rich propane-air flame $(4,5 \%$ of propane) $[8,17]$ are given in Fig.10-12. Formaldehyde, propene, ethylene, acetylene, methane. have been determined among the other intermediate stable products. One should pay attention to the following peculiarities of this flame structure: 1) fuel conversion occurs in the preflame zone, i.e. in the flame zone restricted from one side by the cold boundary of the luminous zone $(650-700 \mathrm{~K})$, and from the other side by the place of noticeable reaction occurrence in the initial combustible mixture; 2) conversion of fuel molecules into intermediate and final products starts as early as the initial temperature of combustible mixture; 3) the major part of the fuel is consumed before reaching the inner boundary of the luminous zone; 4) The temperature profile in the preflame zone differs considerably from the calculated one predicted for conductive heating only, i.e. there occur exothermic reactions.

Basing on the temperature rise the reaction starts at $z=-2.4 \mathrm{~mm}$. Consumption of propane and oxygen is observed simultaneously from $z=-1.4 \mathrm{~mm}$, where the temperature rise is about $8 \mathrm{~K}$. Conversion of $50 \%$ of fuel corresponds to $z=-0.7 \mathrm{~mm}$, where the temperature increases only by $20 \mathrm{~K}$. Simultaneously $\mathrm{CO}_{2}$ is formed, the amount of which is at $z=-0.7 \mathrm{~mm}$ reaches $26 \%$ of the maximum, and $C O$ is formed in less amounts. Original propane almost completely disappears before the luminous zone, which in the classical theories is usually associated with the reaction zone. 


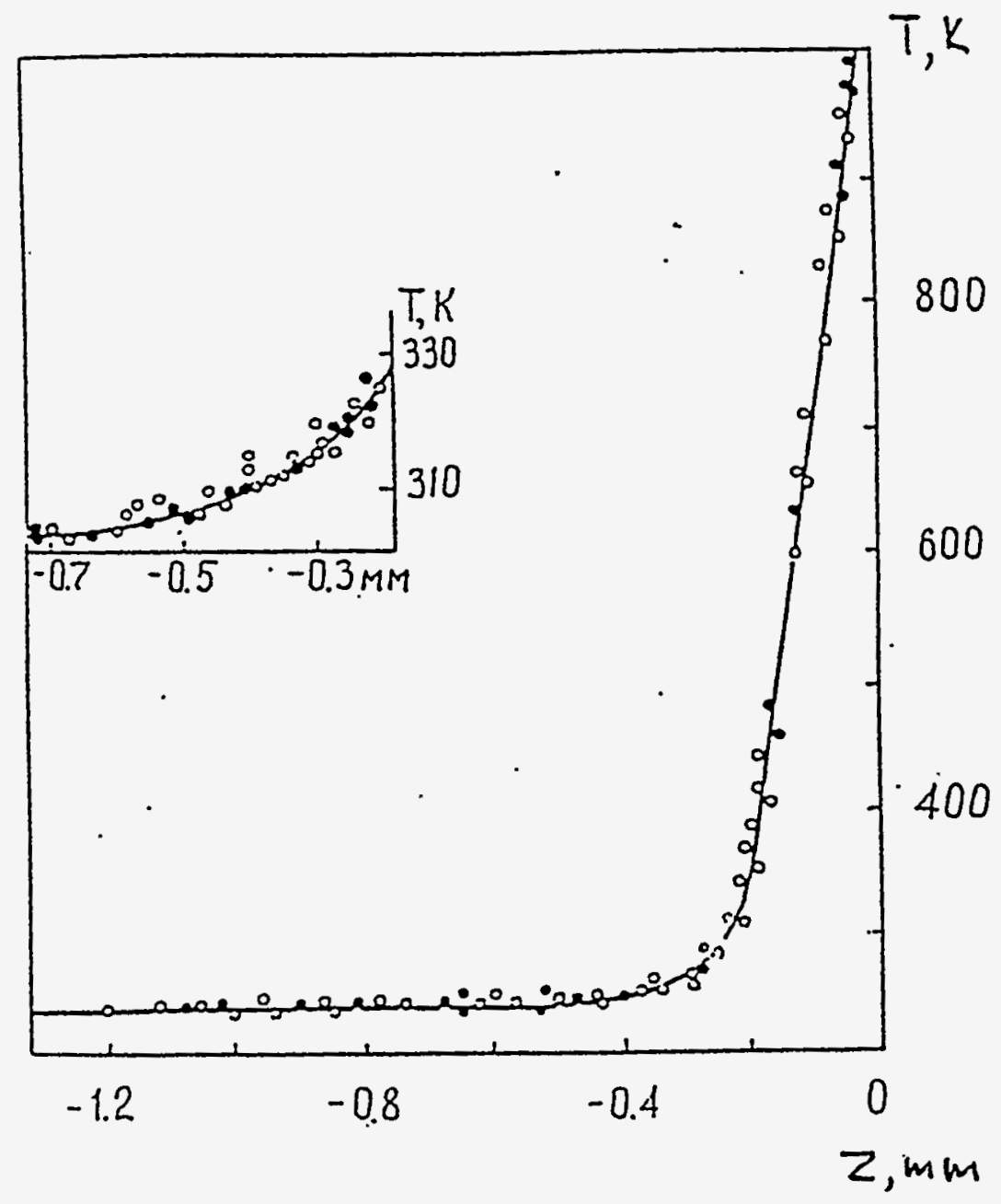

Fig.9. Temperature profiles in a lean acetylene-air flame $\left(4.1 \% \mathrm{C}_{2} \mathrm{H}_{2}\right)$. - observed; - calculated as suggested in the case of conductive heating only. 


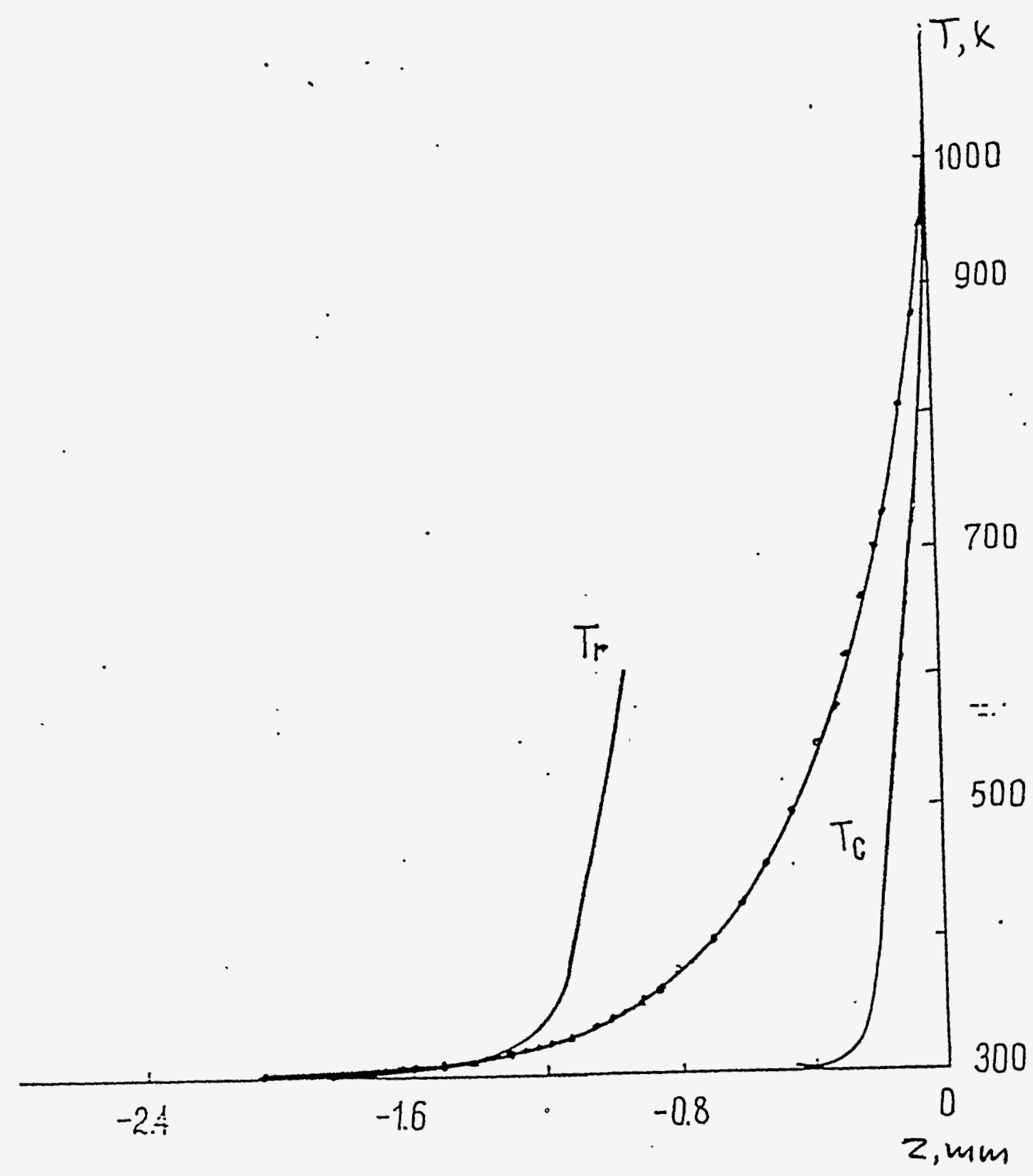

Fig.10. Temperature profiles observed (T) and calculated $\left(T_{C}\right)$, and $\left(T_{r}\right)$ (see text) in the propane flame. 


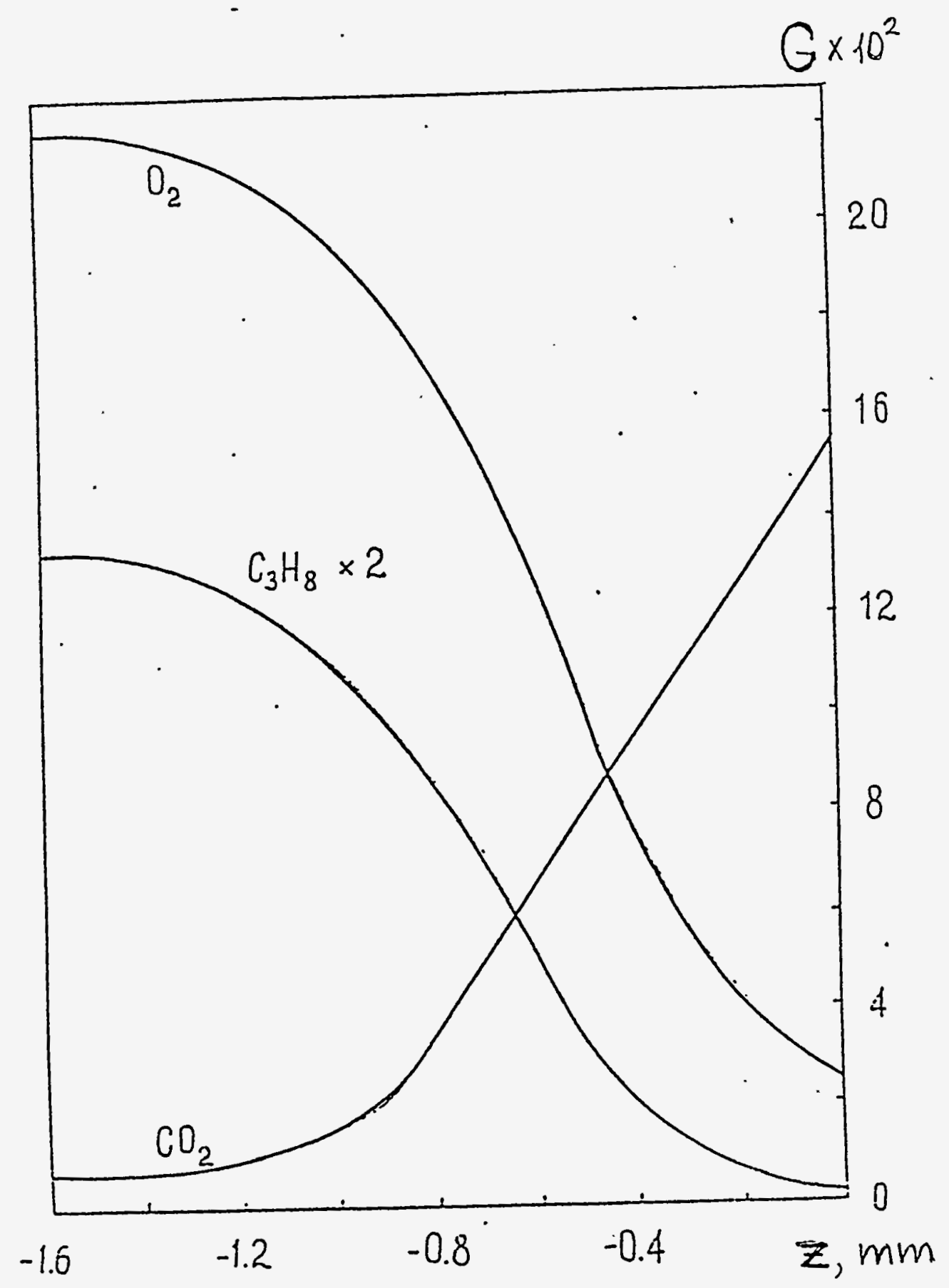

Fig.11. Mass flux fractions (G) of $\mathrm{C}_{3} \mathrm{H}_{8}, \mathrm{O}_{2}$ and $\mathrm{CO}_{2}$ versus distance ( $z$ ) from the inner boundary of luminous zone in a rich propane-air flame $\left(4.5 \% \mathrm{C}_{3} \mathrm{H}_{8}\right)$. 


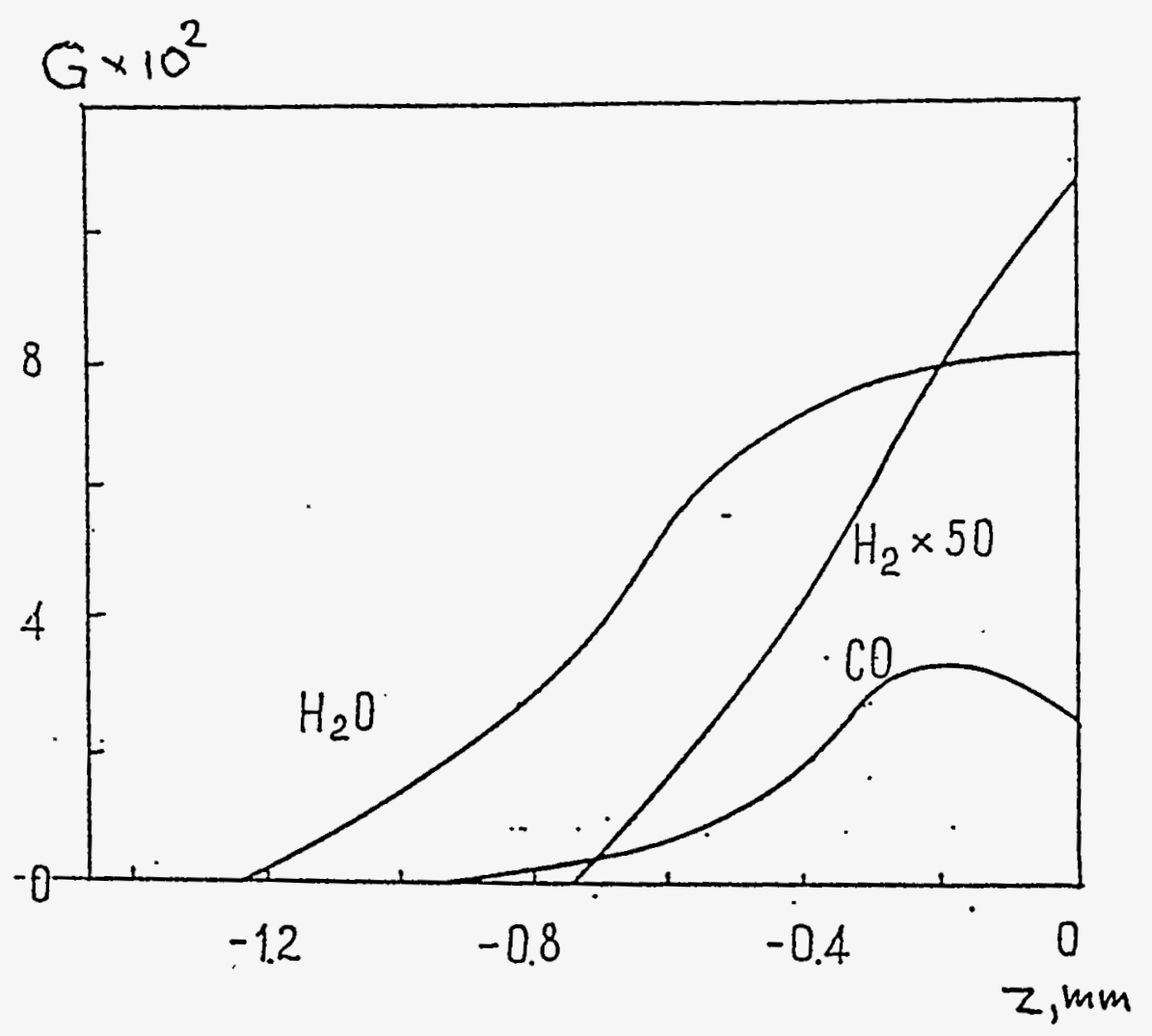

Fig.12. Mass flux fractions (G) of $\mathrm{CO}, \mathrm{H}_{2} \mathrm{O}$ and $\mathrm{H}_{2}$ versus distance (z) from the inner boundary of luminous zone in a rich propane-air flame $\left(4.5 \% \mathrm{C}_{3} \mathrm{H}_{8}\right)$. 
The profile of the heat release rate in the preflame zone is shown in Fig.13, from which it follows that the heat release reaction starts already at $z=-2.4 \mathrm{~mm}$, though a noticeable change in the concentrations of the initial species is detected by mass-spectral analysis only at $z=-1.4 \mathrm{~mm}$; as for the maximum of the heat release rate, it is attained in the luminous zone. The maximum of the heat release.rate and the maximum of the propane conversion rate which is attained at $z=-0.6 \mathrm{~mm}$ are spatially separated.

Hence we may conclude that: 1 ) the luminous zone includes intermediate and final products of the fuel conversion; 2) fuel molecules breaking reactions occur at. low temperatures close to the initial temperature; 3) formation of comparatively large amounts of $\mathrm{CO}_{2}$ and $\mathrm{CO}$ is accompanied by unexpectedly small heating of the mixture.

Expected distribution of temperature calculated for the case of complete release during the formation of $\mathrm{CO}_{2}, \mathrm{CO}, \mathrm{H}_{2} \mathrm{O}$ and other intermediate stable products $\left(T_{r}\right)$ is also given in Fig.10. A sharp disagreement between the calculated and experimental temperature indicates that apart from original substances and stable products there is a great number of unstable intermediates with a large heat content in the preflame zone. Apparently, a considerable part of the thermal effect of the final products formation reactions is used for scission of the fuel molecules $C-C$ bonds, i.e. it passes into the enthalpy of the initial molecules fragments.

The preflame zone reactions are vigorous: half of the propane is consumed during $1.6 \mathrm{~ms}$ at temperatures exceeding the initial temperature not more than by 70K. Obviously, such rates at temperatures close to the room temperature can be reached only in reactions with active particles - atoms and free radicals. Active particles $H, O H$ and $O$, the concentrations of which surpass by several orders equilibrium values, are known to be present in the luminous zone of the hydrocarbon flames. Among them the $H$ atoms have the highest diffusion rate. Apparently, these are the $H$ atoms that can diffuse deeper upstream into the incoming mixture from the luminous zone and initiate the chain of the fuel conversion. That is why study of the $H$ atoms distribution all over the reaction zone of the flame front seem attractive [9].

The distribution of the $\mathrm{H}$ atoms in nearly stoichiometric Bunsen atmospheric pressure propane air flames (4.2\% propane) was studied with the ESR-spectrometer. Inner walls of the sampling 


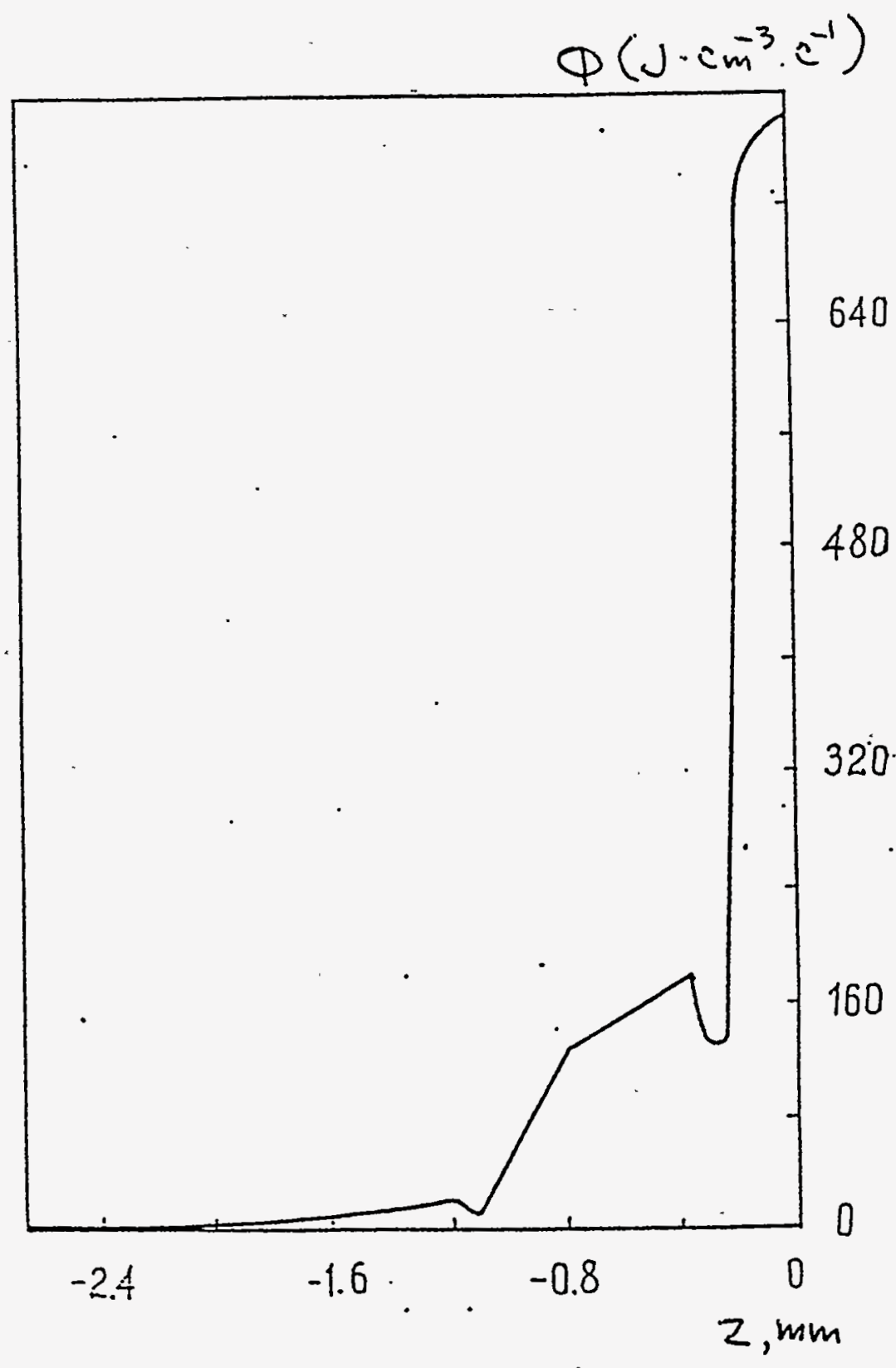

Fig.13. Heat release profile in the propane-air flame: 
heterogeneous destroying of the radicals, and corresponding correction for $\mathrm{H}$ atoms concentration did not exceed 17\%. $\mathrm{H}$ atom concentration profile in luminous and after-burning zone is shown in Fig.14. The maximum concentration is observed in the luminous zone and is found to be $10^{17} \mathrm{~cm}^{-3}$. Unfortunately, direct determination of the $\mathrm{H}$ atom concentration in the preflame zone could not be carried out because of their intensive disappearance in the sampling system in the presence of hydrocarbon fragments and formaldehyde. $\mathrm{H}$ atom concentration has been determined there only indirectly by titrant technique as described below.

In any case, as a result of $\mathrm{H}$ atom diffusion into fresh combustible mixture the formation of peroxy radicals can be expected. The latter were observed in the same flame using the technique of accumulating radicals in matrix from combustion products when cooled with liquid nitrogen [9]. Hydroperoxy and alkylperoxy radical net concentration profile in cold and hot flame zones is given in Fig.15. The change of the ESR-signal shape when sampling from different flame points is likely to indicate that the nature of radicals through the flame front changes as well. The appearance of maximum in the hot zone coinciding with the change of signal shape in the ESR-spectrum may be accounted for the accumulation of the HCO radical [15].

Detection of peroxy radicals in the preflame zone where the temperature of the initial mixture increases by only 10-50 K indicates the occurrence of intensive reactions. It means that in flames, besides already detected $\mathrm{H}_{2} \mathrm{O}, \mathrm{CO}_{2}, \mathrm{CO}$ and $\mathrm{CH}_{2} \mathrm{O}$ the detection of the other oxygen-containing compounds is possible, concentrations of which are below the threshold of the mass spectrometer detectability when analyzing the complex mixture of the combustion products. Polarographic measurements have been carried out using a technique of freezing out the sample from the propane air flame [13]. $\mathrm{H}_{2} \mathrm{O}_{2}$, alkylperoxy compounds, $\mathrm{CH}_{2} \mathrm{O}, \mathrm{CH}_{3} \mathrm{CHO}$ and probably $\mathrm{C}_{2} \mathrm{H}_{5} \mathrm{CHO}$ have been found in samples. The maximum concentrations measured in these experiments have been found to be as follows: $\left[\mathrm{H}_{2} \mathrm{O}_{2}\right]_{\max }{ }^{-0.2 \%},\left[\mathrm{CH}_{3} \mathrm{CHO}_{2} \mathrm{C}_{2} \mathrm{H}_{5} \mathrm{CHO}_{\max }-0.5 \% ;\left[\mathrm{CH}_{2} \mathrm{O}\right]_{\max }{ }^{-}\right.$ $0.1 \%$ [alkylperoxides $]_{\max }-0.06 \%$. Alkylperoxide concentration profile is shown in Fig.16. 


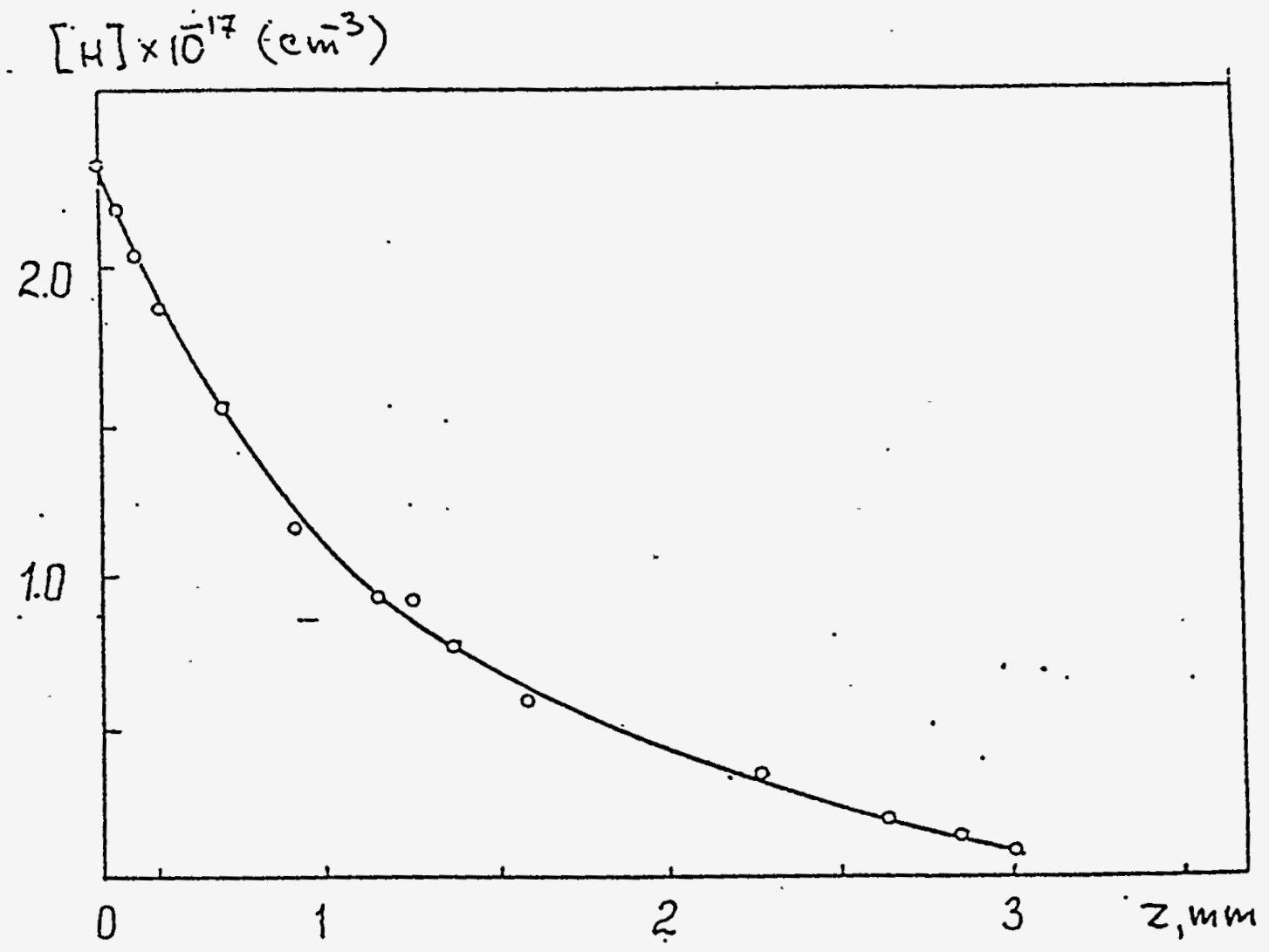

Fig.14. Concentration profile for H-atoms in after-burning zone of propane-air flame $\left(4.2 \% \mathrm{C}_{3} \mathrm{H}_{8}\right)$. 


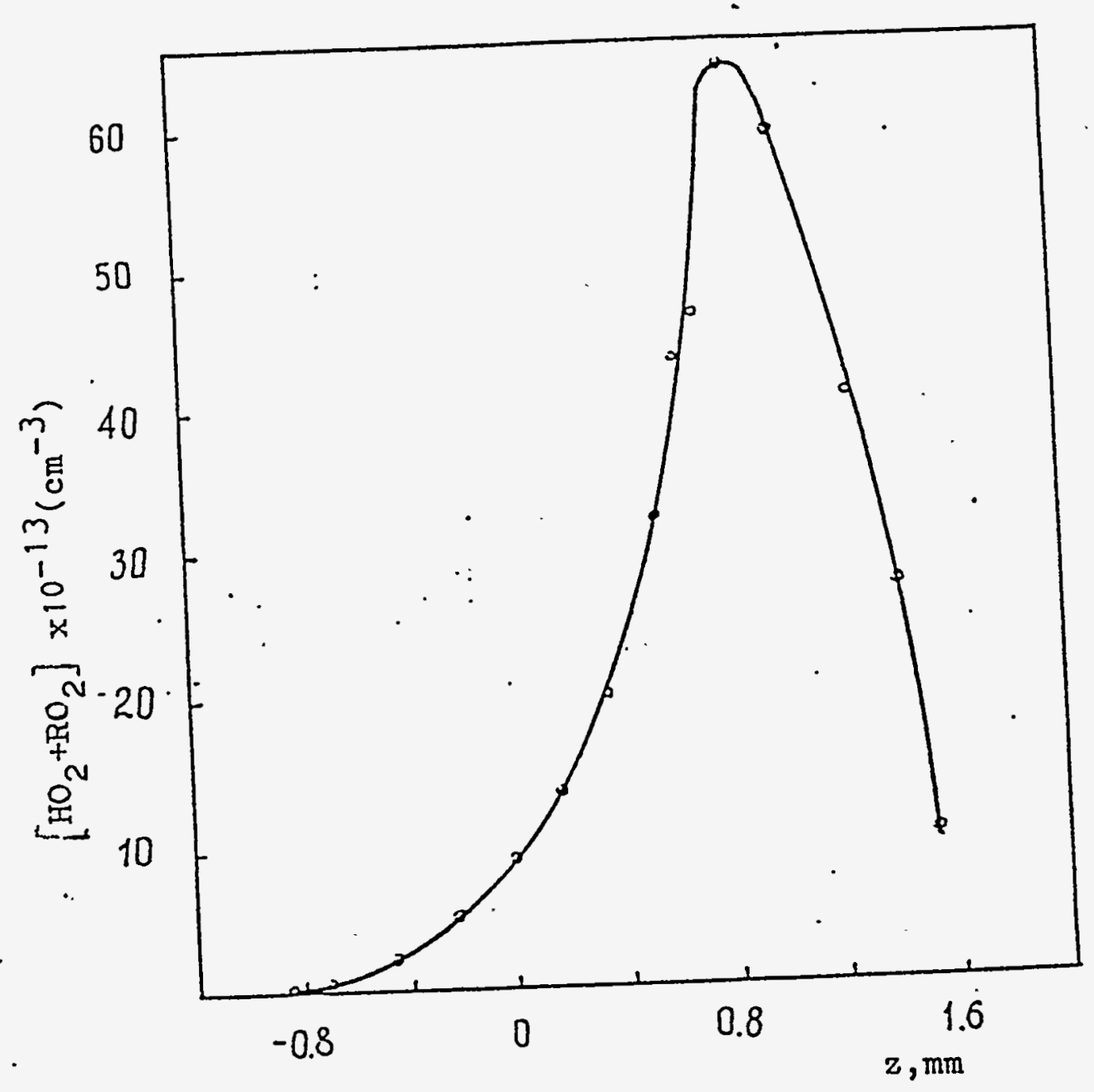

Fig.15. Hydroperoxy and alkylperoxy radicals net concentration profiles in the propane flame. 


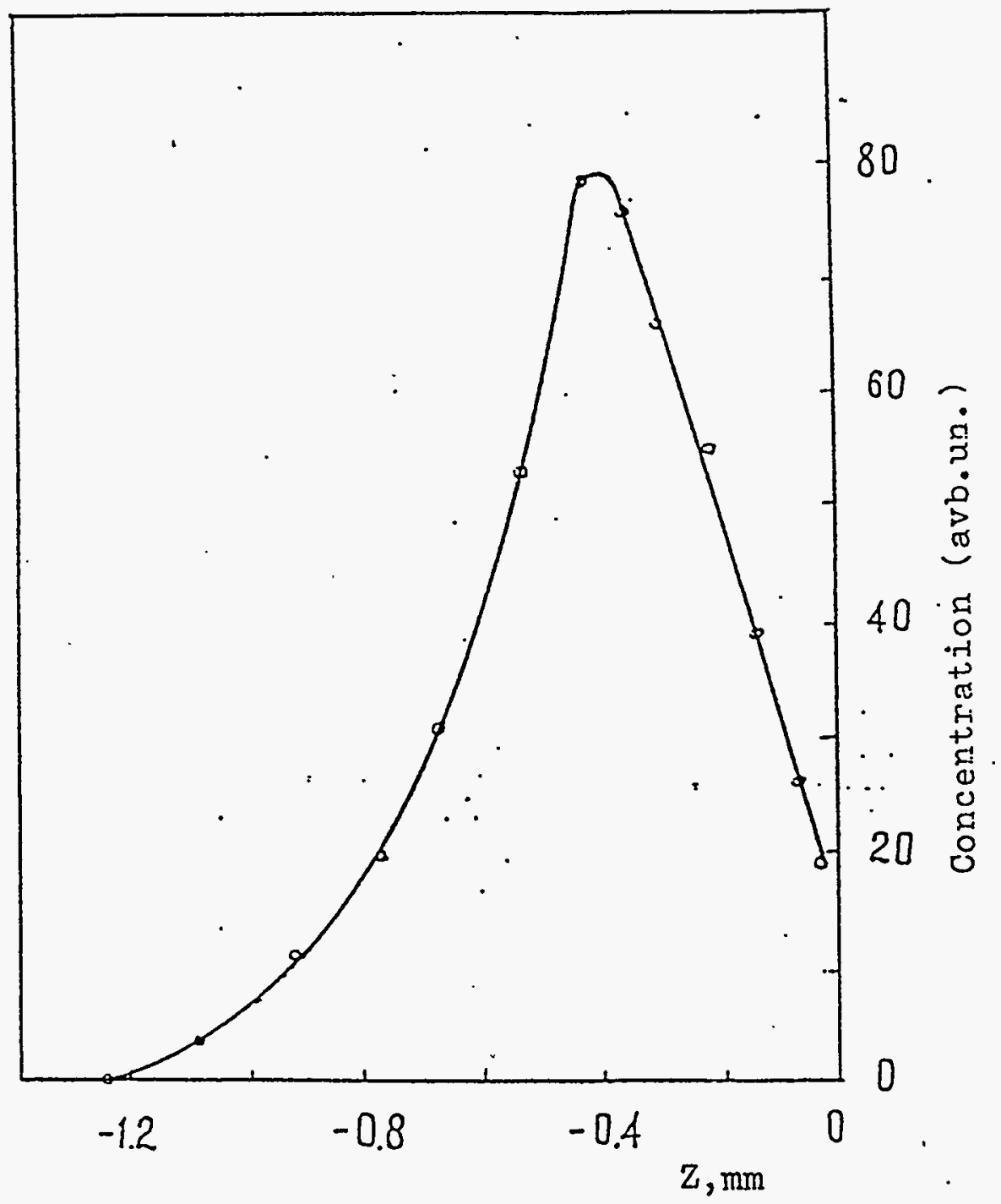

Fig.16. Alkylperoxide concentration profile (relative values) in the propane flame. 
Pentane Flame

Laminar pentane-oxygen-argon flame was stabilized on the conic burner made quartz with the inner diameter of the nozzle being $8 \mathrm{~mm}$. The composition of the initial mixture is $3.2 \% \mathrm{C}_{5} \mathrm{H}_{12}$, $15 \% \mathrm{O}_{2}, 81.8 \%$ Ar [18]. The excess-fuel coefficient is 1.7. Normal burning rate is $33.4 \mathrm{~cm} / \mathrm{s}$. Introduction of the liquid fuel in the form of vapor was done by means of a.'specially designed evaporation cell. The composition of the initial combustible mixture was being checked by the mass-spectrometer.

The temperature $r i s e$ is registered from the distance $z=0.65 \mathrm{~mm}$ (Fig.17). The concentration profiles of the compounds through the flame fronts are given in Fig.18. Deviation in the balance of the elements concentration constitutes $\pm 10-15 \%$.

Results obtained in the absence of screening effect (dotted lines in Fig.18) and with screening of flame by the argon flux have been compared. The difference was shown to occur in the after-flame gases zone for $\mathrm{CO}$ and $\mathrm{H}_{2}$, the concentration of which reach the plate in the screened flame. The start of the fuel and oxidizer conversion is observed at a distance, $z=-1.2 \mathrm{~mm}$ and $z=-0.8 \mathrm{~mm}$, correspondingly.

Maximum of the fuel consumption rate is noticed at a distance $z=-0.45 \mathrm{~mm}$ at $\mathrm{T}=460 \mathrm{~K}$ (Fig.19). There are detected maxima of the hydrocarbon products formation rates: propene, ethylene, methane, formaldehyde. Fuel disappearance is completed on the inner boundary of the luminous zone.

Maximum rate of the oxidizer's disappearance is registered at $z=-0.2 \mathrm{~mm}, \mathrm{~T}=950 \mathrm{~K}$. In the region of maximum oxygen consumption maximal amounts of $\mathrm{CO}, \mathrm{CO}_{2}, \mathrm{H}_{2}, \mathrm{H}_{2} \mathrm{O}$ are formed. Maximum of the heat release rate is somewhat shifted to the luminous zone $(\mathrm{T}=1600 \mathrm{~K})$ (Fig.20).

\section{Methane Flame}

Laminar methane-oxygen-argon flames were stabilized over conic burners made of Pyrex or quartz with the nozzle inner diameter $8 \mathrm{~mm}$. The following mixtures were studied (see Table 1).

Based on the obtained experimental data such as concentrations and temperatures profiles by means of the method suggested in [5], in quasi-unidimensional approximation there were calculated the mass flux profiles taking into account diffusion of the components and gradients of temperature, concentrations, 


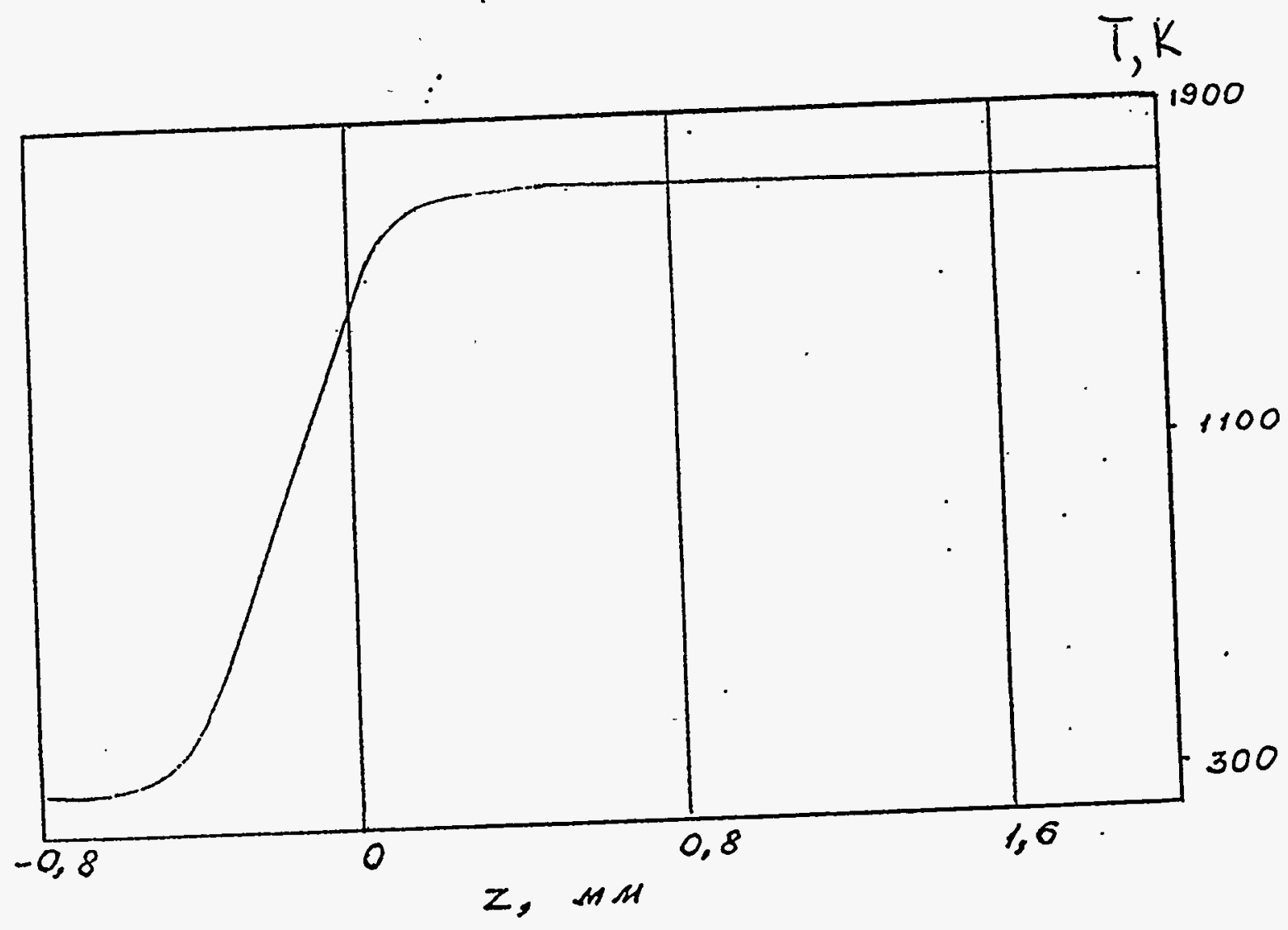

Fig.17. Temperature profile in pentane-oxygen-argon flame $(\alpha=1.7)$. 


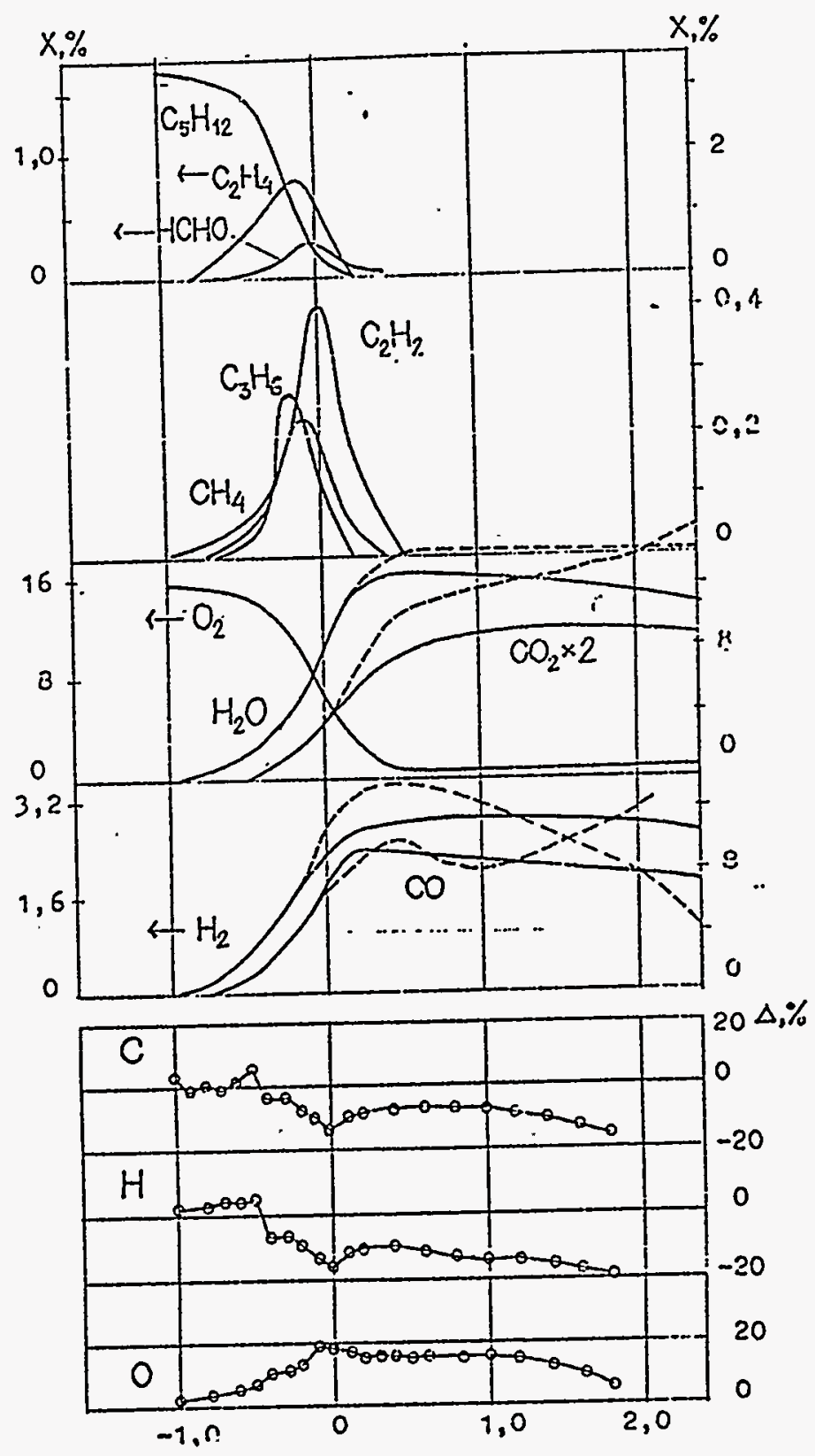

Fig.18. Concentration profiles in the pentane flame. 


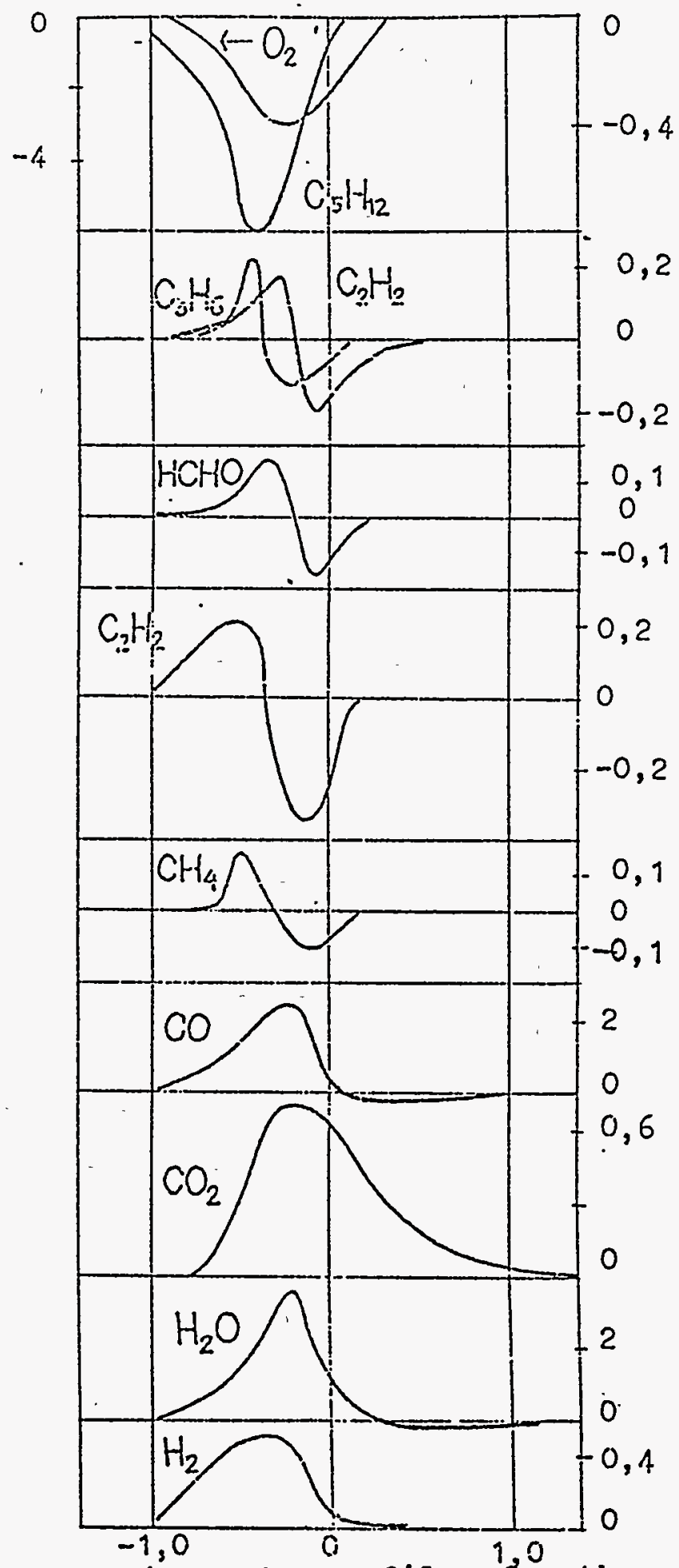

Fig.19. Net reaction rate profiles for the pentane flame. 


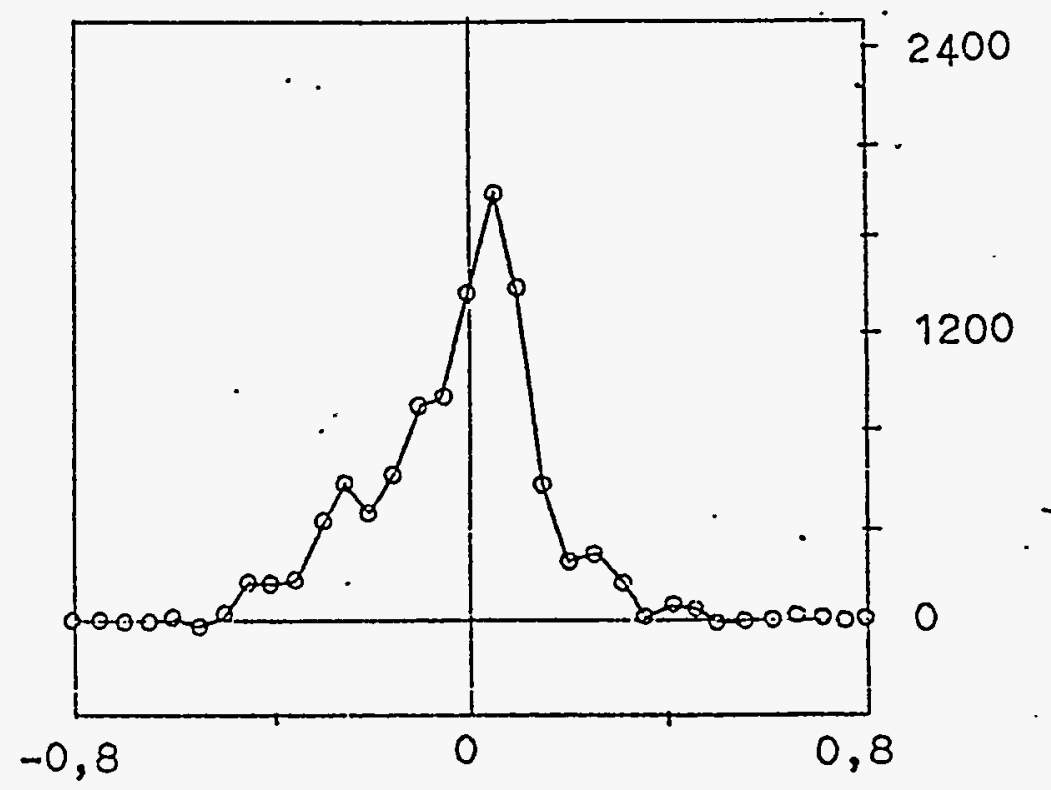

Fig.20. Local heat release rate for the pentane flame. 
determined the conservation balance of the $\mathrm{C}, \mathrm{H}, \mathrm{O}$ elements to check correctness of the results, and also volumetric heat release rate in the flames and thermal components of the enthalpy balance in every point of the flame front [19].

Table 1

Characteristics of the Initial Combustible Mixtures

(initial temperature is $298 \mathrm{~K}$ )

\begin{tabular}{|ccccc|c|c|}
\hline & \multicolumn{4}{c}{$\begin{array}{c}\text { Mixture } \\
\text { composition } \\
\text { (vol.\%) }\end{array}$} & Excess-fuel & $\begin{array}{c}\text { Normal } \\
\text { burning } \\
\text { coefficient } \\
\text { rate } \\
\text { (cm/s) }\end{array}$ \\
\hline & $\mathrm{CH}_{4}$ & $\mathrm{O}_{2}$ & $\mathrm{Ar}$ & $\mathrm{C}_{2} \mathrm{~F}_{4} \mathrm{Br}_{2}$ & & \\
\hline 1 & 10.5 & 16.9 & 72.6 & - & 1.30 & 43.4 \\
2 & 10.5 & 16.9 & 72.1 & 0.55 & 1.30 & 30.2 \\
3 & 7.8 & 14.5 & 77.7 & - & 1.07 & 50.7 \\
4 & 7.8 & 14.5 & 77.3 & 0.40 & 1.07 & 37.1 \\
5 & 9.3 & 22.0 & 68.7 & - & 0.80 & 29.8 \\
\hline
\end{tabular}

Fig.21 gives the temperature profiles in the methane flame, averaged by the results of several experiments. Start of the temperature rise was noticed at a distance $z=-0.55 \mathrm{~mm}$ from the inner boundary of the luminous zone. Addition of small amounts of the inhibitor $(4.5 \mathrm{~mol} \%$ vs fuel) reduces the temperature in the inner boundary of the luminous zone by $250 \mathrm{~K}$. There is also given the temperature profile in the preflame zone calculated in accordance with the Mikhelson's equation supposing the absence of the chemical reactions. The fact that the experimental profile exceeds the calculated one testifies to the occurrence of chemical reactions before the mixture reaches a high temperature zone. The same figure demonstrates profiles distribution of the stable compounds mass fluxes in a rich methane flame $(\alpha=1.30)$.

By the dotted lines there are indicated values referring to the inhibited methane flame.Conversion of a significant fuel mass occurs in the preflame zone. The process is completed in the luminous zone before the system reaches maximum temperature. on the inner boundary of the luminous zone the amount of the oxygen which unreacted is $22 \%$. A noticeable disappearance of the inhibitor addition starts at the initial temperature. In the flame 


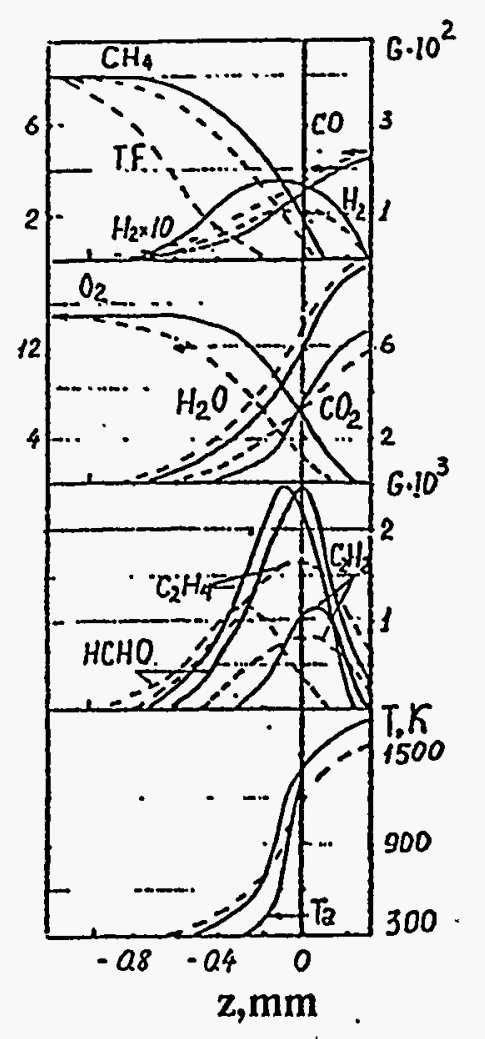

Fig.21.

$\phi=1.30$

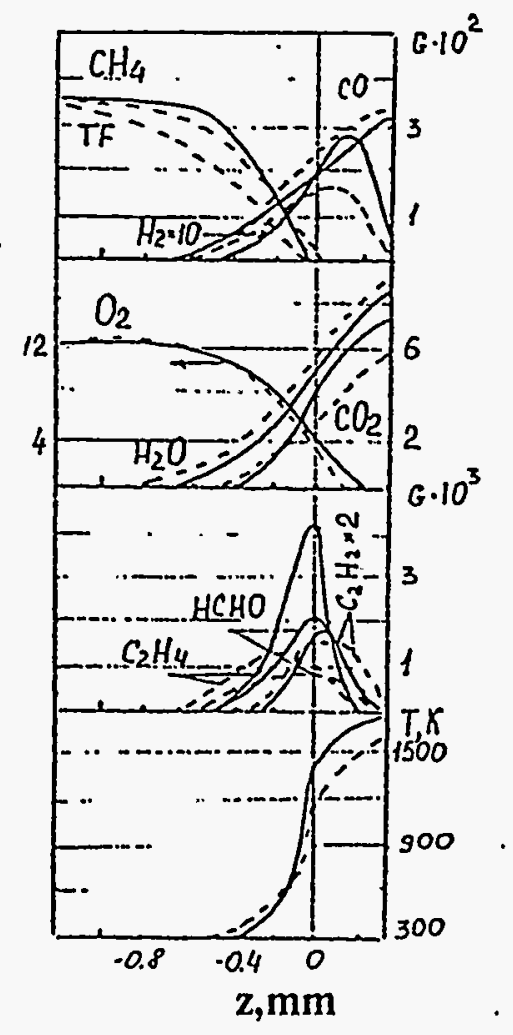

Fig.22.

$\phi=1.07$

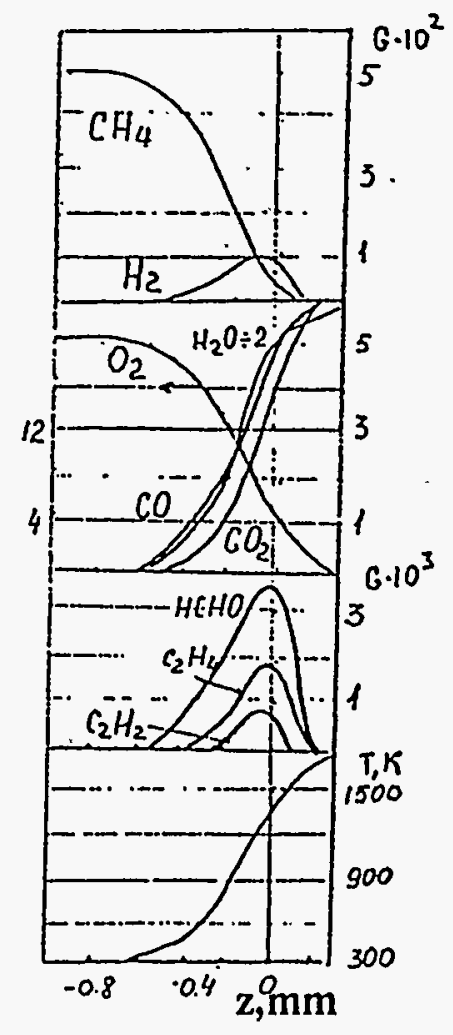

Fig.23.

$\phi=0.80$

Mass flux fractions and temperature profiles for the methane flames.

Dashed lines - inhibited flames. 
with the addition of tetrafluorodibromide ethane (TF) compared to the non-inhibited one, there is observed somewhat earlier growth of the concentration profiles of carbon oxide and dioxide, formaldehyde, ethylene, hydrogen and water.

Fig.22 gives the temperature profiles and the profiles of mass flux profiles in the methane flames with $\alpha=1.07$. The composition of the detected products is analogous to a richer flame, but the width of the high-temperature zone is less and is $0.6 \mathrm{~mm}$. Fig.23 gives the temperature and mass flux profiles in a lean methane flame $(\alpha=0.80)$. Contrary to the above flames here the appearance sequence of two intermediate products is different: first appears formaldehyde, then - ethylene. Fig.24 gives the profiles of the volumetric heat release rates in the methane flames. Maximum of the heat release rate is reached before the luminous zone where maximum rates of the oxygen consumption and maximum formation rates of the water and carbon dioxide are noted.

Fig.25 gives the hydrogen concentration profile in the preflame zone of the rich methane flame. The curve plateau can apparently be associated with an additional source of the $H$ atoms formation in the low-temperature reaction zone. For this methane flame an energy balance was estimated. Fig.26 gives. the calculation data on convection, diffusion and conduction components of the total enthalpy flux throughout the flame front. The width of the low-temperature zone before the luminous zone in three studied methane flames is much narrower ( twice) than in the above propane, hexane and pentane flames.

As normal burning rates of the studied methane-oxygen-argon mixtures are close by their value to the analogous flames of the other hydrocarbons, then it should be expected that the rate of methane conversion will also be close to those of other hydrocarbons in the reaction low-temperature zone. In such a case a narrow preflame zone is accounted for by the absence of the $c-c$ bond in the original fuel molecule and a somewhat greater energy of the $\mathrm{C}-\mathrm{H}$ bond compared to the other hydrocarbons.

study of the premixed laminar flames of methane as well as analogous long-chained hydrocarbons flames showed that fuel conversion starts practically from the initial temperature, and before reaching the luminous zone the fuel is almost totally consumed forming not only intermediate but also final combustion products. 


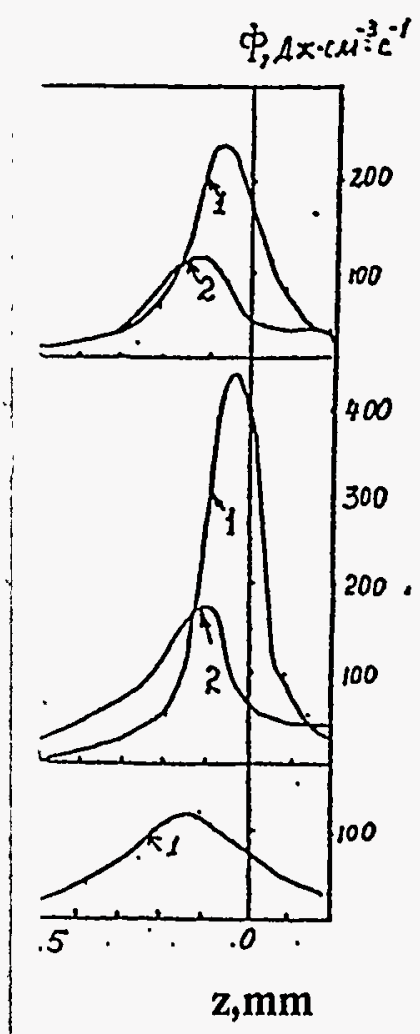

Fig.24

Local heat release profiles in the methane flames.

a) $\phi=1.30$ b) $\phi=1.07$ c) $\phi=0.80$

1 - with $\mathrm{C}_{2} \mathrm{~F}_{4} \mathrm{Br} 2$

2 - without $\mathrm{C}_{2} \mathrm{~F}_{4} \mathrm{Br}_{2}$

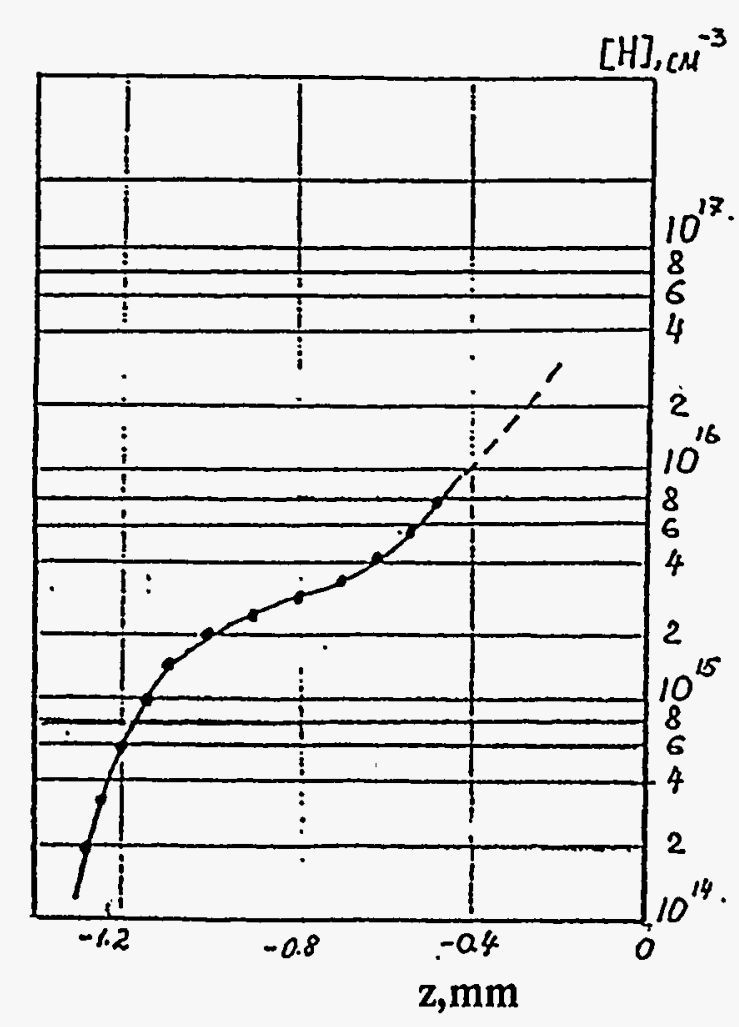

Fig.25

$\mathrm{H}$-atoms concentration profile for the methane flame. $\phi=1.30$

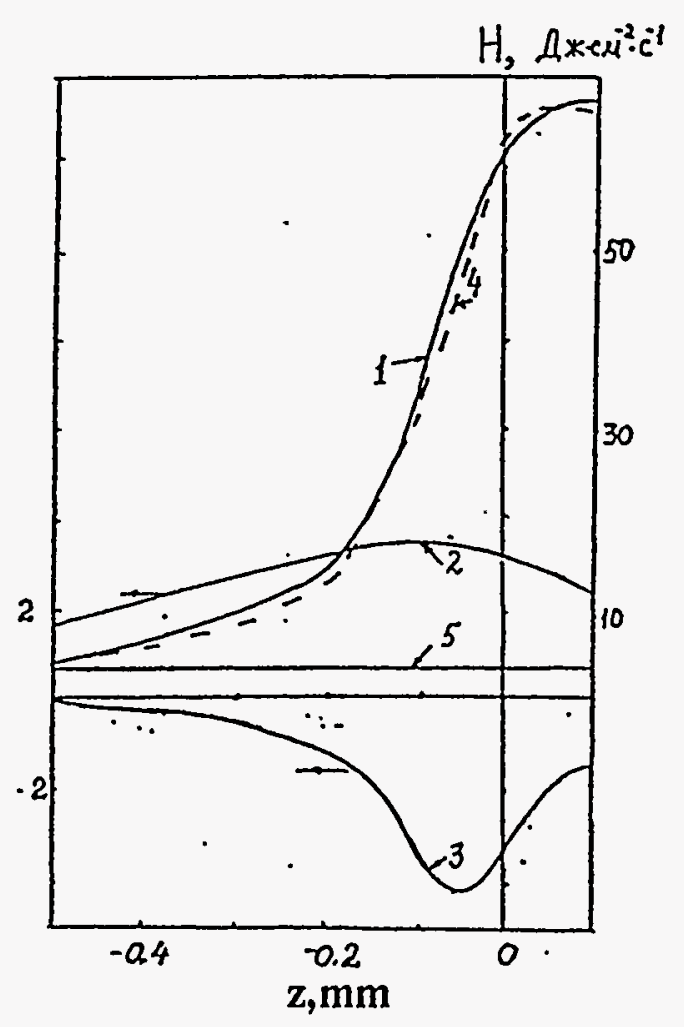

Fig.26

Fluxes profiles for the methane flame. $\phi=1.30$. 1 - convection; 2 - diffusion; 3 - heat conductivity; $4=1+2+3$; 5 - initial flux 
As it was shown earlier [20], with the addition of 27 vol.\% TF vs propane, all the fuel conversion processes noticeably shift to the high-temperature zone, and disappearance of the inhibitor starts from the place where the fuel consumption has begun in the uninhibited flame. With significantly lower concentrations of the inhibitor (only 4 vol.\% vs fuel) [19] the additive's effect upon the flame front structure is ambiguous. The inhibitor effectively reduces burning rate (by $30 \%$ ) and the temperature on the inner boundary of the luminous zone (by 200-250K), sharply decreases the value of the heat release rate maximum. However, at the same time, alongside with such a deceleration in cooler layers there is observed earlier rise of the temperature and earlier appearance of the intermediate and even final combustion products. Depending on the amount and conditions of combustion a well-known inhibitor (TF) can act in two ways. Apparently, at small concentrations TF-inhibiting action appears to be caused by the delay of only low-temperature stages in the combustion wave. With the increase of the TF concentration in the mixture the inhibitor's activity deviates from the linear one. This is due to the increase in the concentration of free valences which are obtained during inhibitor's conversion due to the reaction of its molecule with the hydrogen atoms.

Effect of the Inhibitors and Promoters

Autocatalytic reactions are effected by the inhibitors stronger than thermolautoaccelerated ones. That is why, adding inhibitors into combustible mixture, we depress or delay lowtemperature reactions. The beginning of the fuel consumption in such flame should be shifted to the higher temperature zone. The width of the preflame zone is reduced and that of the thermal zone increased, as a significant fraction of fuel enters the latter zone without preliminary fuel processing in the low-temperature zone. Thus, we can expect the inhibitor action upon the front structure to be analogous to the enrichment of the initial mixture with fuel. Discovery of the low-temperature reaction zone in the atmospheric hyarocarbon flames allows to have a new look at the phenomena of inhibition and promotion of combustion, the mechanism of which is thought to have corresponding reactions only in the high-temperature zone. Fig.27 shows the temperature profiles for uninhibited and TF inhibited propane-air flame (the composition of 


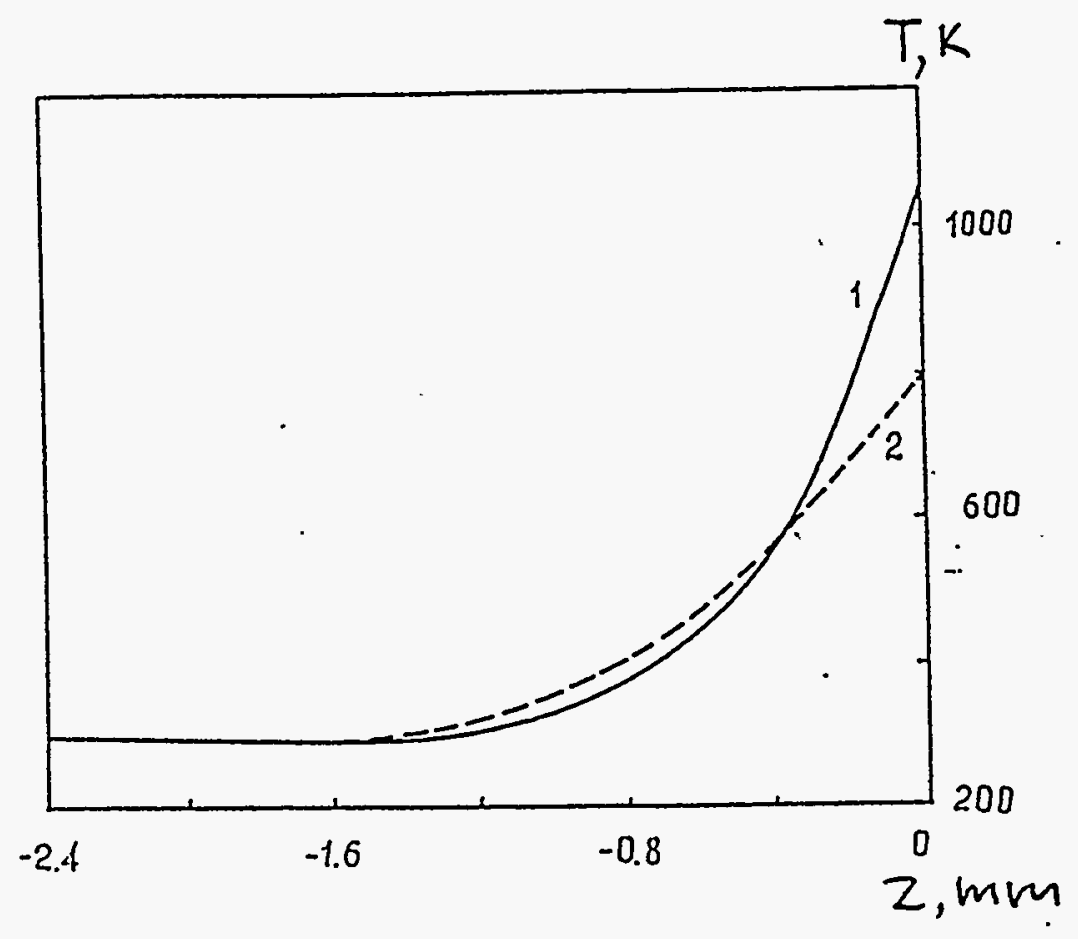

Fig.27. Temperature profile propane-air flame.

(1) clean (4.5\% - $\mathrm{C}_{3} \mathrm{H}_{8} ; 95.5 \%$ - air);

(2) inhibited - $\left(4.5 \%-\mathrm{C}_{3} \mathrm{H}_{8} ; 94.3 \%\right.$ - air; $\left.1.2 \%-\mathrm{C}_{2} \mathrm{~F}_{4} \mathrm{Br} 2\right) \cdot$ 
the combustible mixture: $4.5 \%$ of propane, $94.3 \%$ of air, $1.2 \%$ of TF) [20]. The temperature at the inner boundary of the luminous zone in the inhibited flame is by $270 \mathrm{~K}$ lower than in the uninhibited one. The normal burning rate decreases with inhibition from $42 \mathrm{~cm} / \mathrm{s}$ down to $22 \mathrm{~cm} / \mathrm{s}$. Significant variations have been noticed in the mass fluxes profiles of all the stable compounds in the preflame zone. Fig.28 gives the mass flux profiles of $\mathrm{C}_{3} \mathrm{H}_{8}$ ' $\mathrm{O}_{2}, \mathrm{CO}_{2}$ and $\mathrm{CO}$ for both flames, and Fig.29 the mass flux profile of the inhibitor (TF). Beginning of the consumption of propane and oxygen and also beginning of the dioxide and carbon oxide formation are shifted to wards the luminous zone for $0.4 \mathrm{~mm}$, and, in contrast to the uninhibited flame, the amount of the oxygen remaining at the inner boundary of the luminous zone increases twice. The inhibitor starts to disappear a bit earlier than propane and oxygen, at the temperature insignificantly exceeding the room temperature. The main intermediate product of the inhibitor conversion is $\mathrm{C}_{2} \mathrm{~F}_{4}$, but $\mathrm{HF}$ and $\mathrm{HBr}$ were not found due to their strong adsorption on the walls of the sampling system. Judging by the composition of the detected products, in the preflame zone TF is consumed only as a result of the reaction with the hydrogen atoms.

In general, the effect of the inhibitor (TF) on the structure of the low-temperature reaction zone of the propane-air flame is not confined only to the deceleration of the fuel and oxidizer consumption, but also to the deceleration of the disappearance of the intermediate substances - hydrocarbons and co. some acceleration of these processes is achieved due to their shift to wards the high-temperature zone.

In the propane-air flame, inhibited by diethylamine (composition of the combustible mixture: $4.5 \%$ of propane, $94.7 \%$ of air, $0.8 \%$ of diethylamine) [21] the effect of the inhibitor upon the structure of the low-temperature reaction zone appeared to be quite similar to the one just described for TF [20]. Thus, study of the flame structure with the homogeneous inhibitors shows again that the main process of the fuel molecules acking with simultaneous formation of intermediate and final combustion products occurs in the preflame zone. The inhibitor molecules start being disappeared at a significant distance from the luminous zone simultaneously with the fuel and oxidizer consumption at the initial temperature of the combustible mixture, 


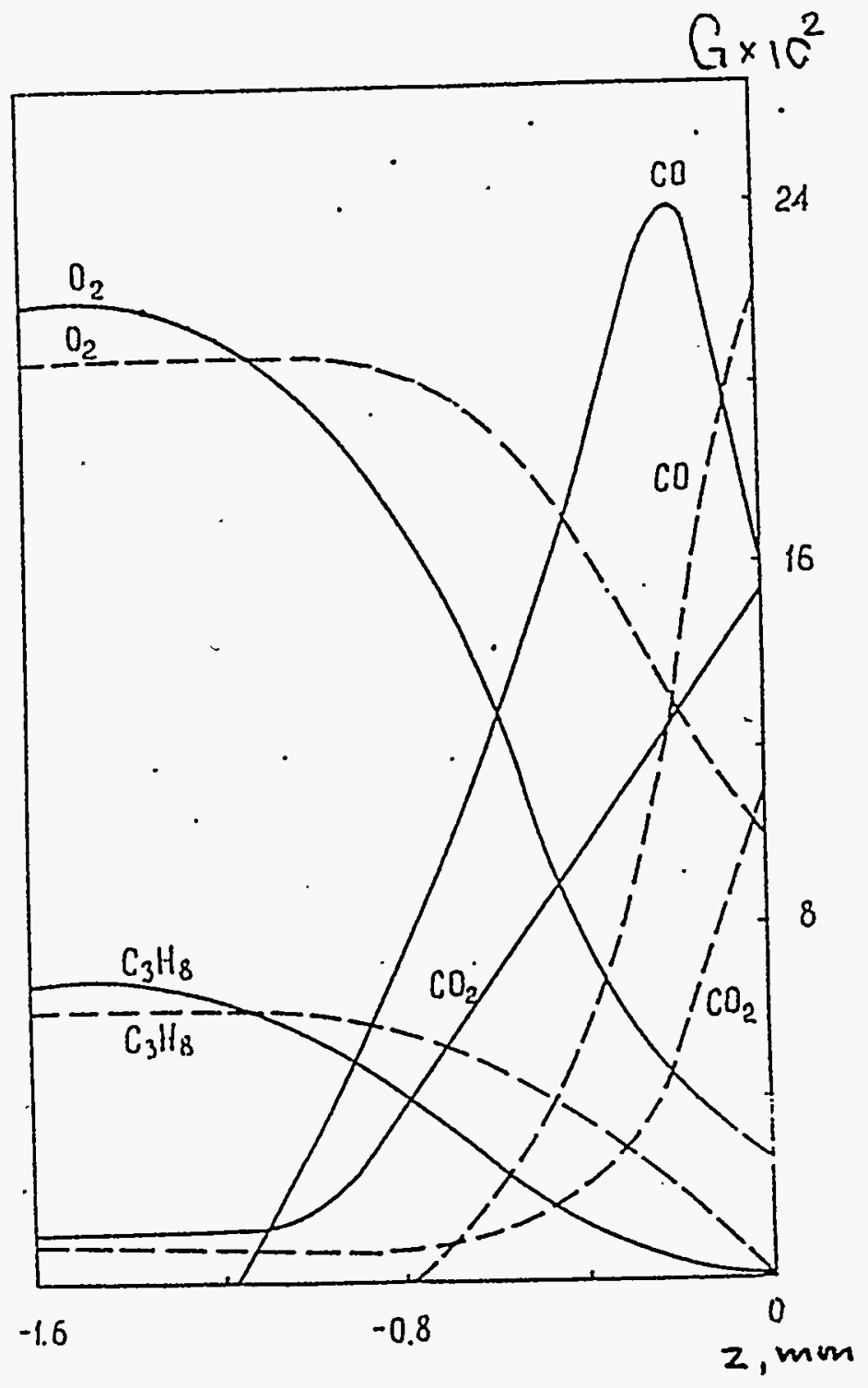

Fig.28. Mass flux fractions profile in propane-air flames. dashed line - inhibited flame; solid line - clean flame. 


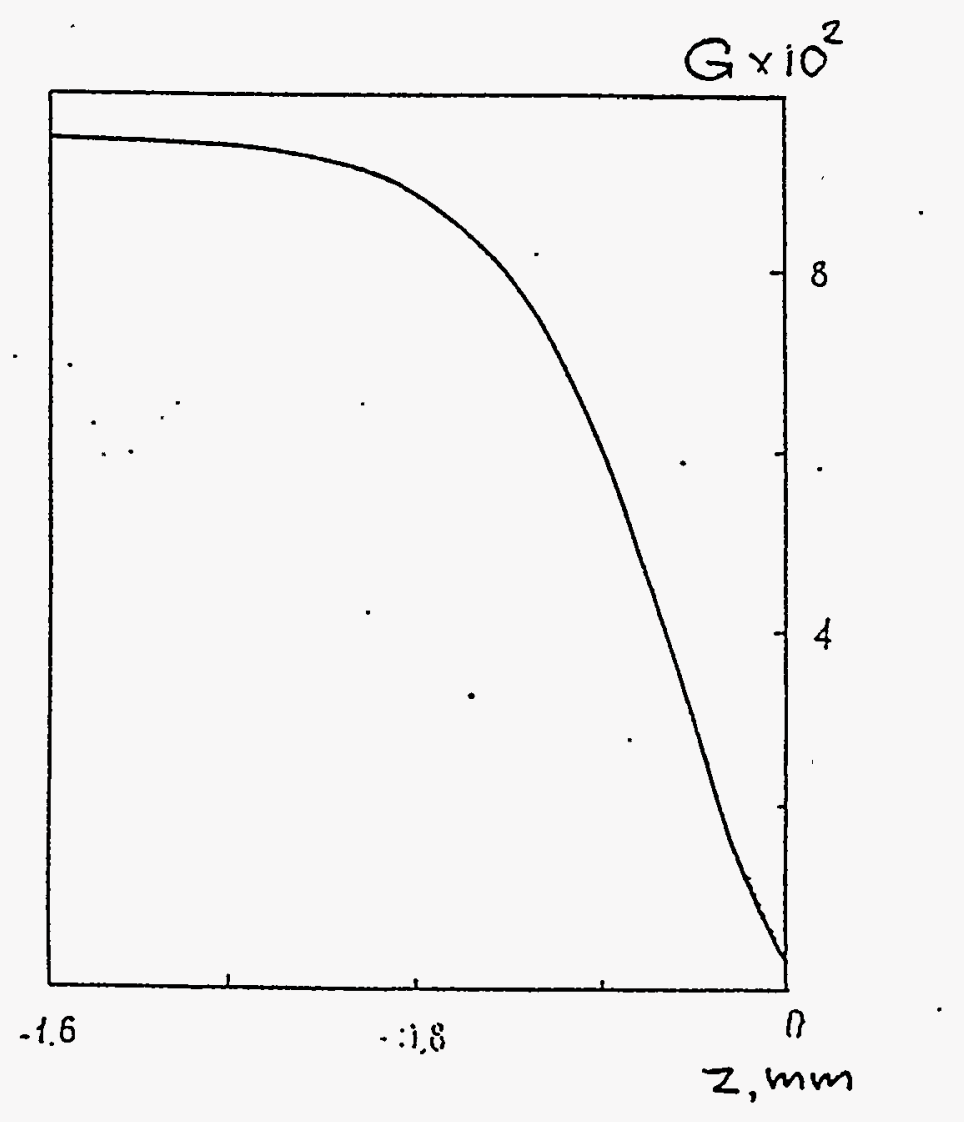

Fig.29. Mass flux fraction profile for $\mathrm{C}_{2} \mathrm{~F}_{4} \mathrm{Br} 2$ in inhibited propane-air flame. 
which excludes the necessary of taking into account thermal decomposition. Hence, not only the products of the inhibitor conversion in the flame has inhibiting effect, as it has earlier been considered, but also the original inhibitor itself, which is totally consumed before it reaches the luminous zone.

Inhibiting effect is usually attributed to the thermal or conversion of the active particles leading the combustion chain into less active ones. Then, disappearance of the inhibitor in the preflame zone corresponds to the decrease of the active particles concentration in it, which should decelerate the rate of the fuel consumption and heat release. In fact, it is apparent from Fig.30 that the heat release rate on the boundary of the luminous zone at inhibition decreases sharply, spatial separation of the fuel consumption rate maximum and of the heat release rate maximum being observed again. Penetration of large amounts of the intermediate products into the high-temperature reaction zone decreases the temperature on the inner boundary of the Iuminous zone, but the equilibrium flame temperature is not almost changed. The same results have also been obtained at the combustion inhibition by salts powders [22]. Inhibiting effectiveness of a number of salts was shown to depend not only on their chemical nature but also upon the particle net surface area increasing with the growth of the latter. This, undoubtedly, indicates a heterogeneous nature of the process. The equilibrium flame temperature is not changed and spectral measurements illustrate decrease in the emission intensity at the $\mathrm{OH}$ radical with the increase in the burning rate. As the efficiency of such inhibitors drops at the enrichment of the flame with fuel, it can be assumed that during inhibition there occurs growth in the oH radicals death on the surface of the salt particles increases.

Investigated promotors such as cyclohexylnitrate (CHN) and isopropylnitrate (IPN) depending on the concentration in the combustible hexane-air mixture and the ratio of fuel/oxidizer can both increase and decrease the burning rate [23]. In small concentrations alkyl-nitrates promote burning and in rather large ones they inhibit it. The structures of two hexane-oxygen-argon mixtures with CHN additives (compositions of the combustible mixtures: 1) $2.0 \%$ of hexane, $0.1 \%$ CHN, $20.8 \%$ of oxygen, $77.1 \%$ of argon; 2) $1.8 \%$ of hexane, $0.7 \%$ of CHN, $19.3 \%$ of oxygen, $78.2 \%$ of argon) have been studied. In the first case burning was promoted, 


$$
\mathrm{K}\left(\mathrm{mole}: \mathrm{cm} \cdot \mathrm{c} \times 10^{3}\right) \quad\left(\mathrm{J} \cdot \mathrm{cm}^{-3} \mathrm{c}^{-1} \cdot \mathrm{x} \times 10^{-2}\right)
$$

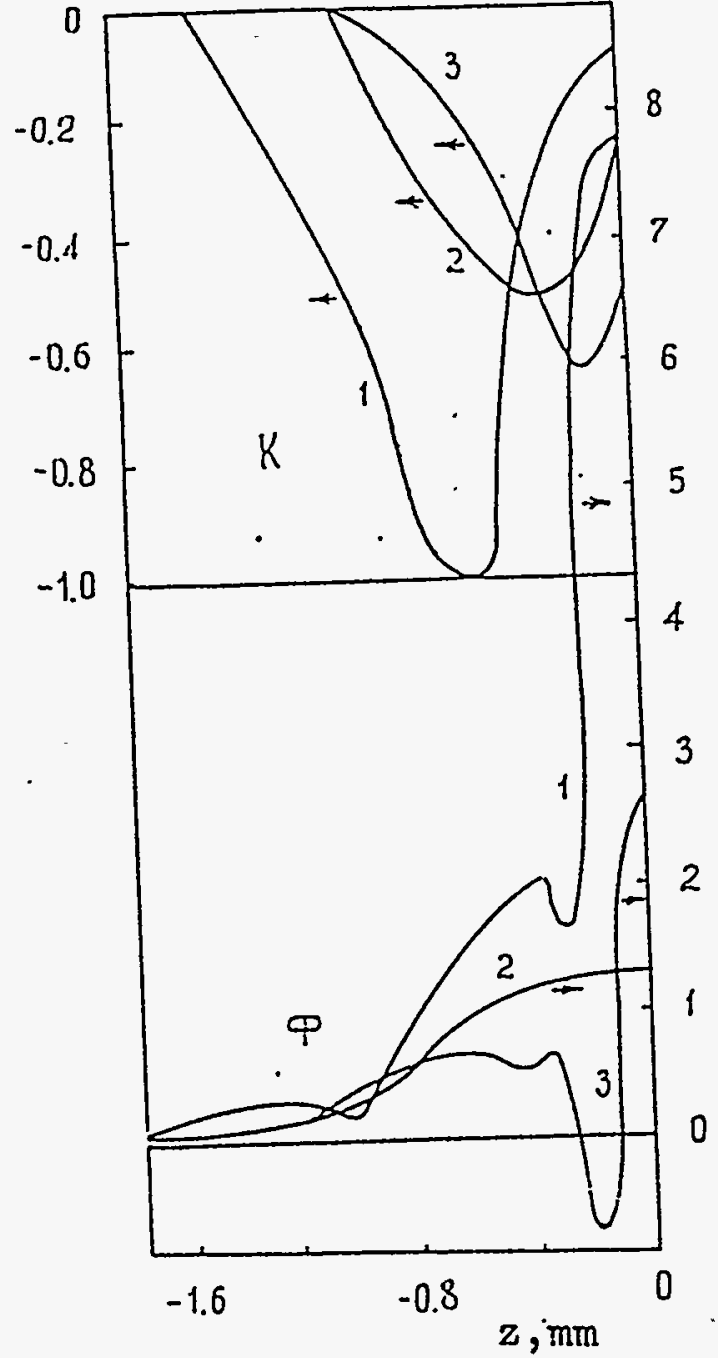

Fig.30. Heat release rate arid propane disappearance net rate profiles for the clean and two inhibited propane-air flames. (I) clean $\left(4.5 \% \mathrm{C}_{3} \mathrm{H}_{8} ; 95.5 \% \mathrm{air}\right)$;

(2) inhibited by $\mathrm{C}_{2} \mathrm{~F}_{4} \mathrm{Br}_{2}$ (4.5\% $\mathrm{C}_{3} \mathrm{H}_{8} ; 94.3 \% \operatorname{air} ; 1.2 \% \mathrm{C}_{2} \mathrm{~F}_{4} \mathrm{Br}_{2}$ );

(3). inhibited by $\left(\mathrm{C}_{2} \mathrm{H}_{5}\right)_{2} \mathrm{NH}$ (4.5\% $\mathrm{C}_{3} \mathrm{H}_{8} ; 94.7 \%$ air, $\left.0.8 \%\left(\mathrm{C}_{2} \mathrm{H}_{5}\right)_{2} \mathrm{NH}\right)$. 
in the second one - inhibited. In both flames the preflame zone width proved to be approximately the same and is about $1.1 \mathrm{~mm}$ which is twice less than in the flame without any additives and which is typical for inhibited flames $[24,25]$. As well as in the other studied flames, fuel conversion accompanied by the intermediate and final products formation starts in the preflame zone at the initial temperature of the combustible mixtures However, the temperature at the inner boundary of the luminous zone in the flames with the additives does not almost differ from that in the flame without any additives.

All the mentioned peculiarities can be accounted for by the fact that in the flames with alkylnitrates addition, in the lowtemperature reaction zone both inhibition and promotion take place the former being conditioned by the interaction of the active particles in the high-temperature zone with nitrogen oxides which are the final products of the promotor conversion, and the latter ones-by the interaction of the active particles with the molecules of the promotor itself. It is apparent that both types of the process are to some extent spatially separated but they effect each other through convection and diffusion conterflows. Increase in the alkylnitrates concentration is accompanied by the slower growth of the promoting effect compared to the inhibiting one, due to the increase in the nitrogen oxides concentration close to the luminous zone, which finally leads to the domination of the latter.

\section{Energetics of the preflame zone processes and}

distribution of hydrogen atoms

The presence of the active particles in the flame, when determining the composition profiles of stable substances only", is not.detected by the balance of elements, for after sampling free radicals recombine on the walls of the sampling system and contribute to the measured concentrations of stable substances. Relatively small concentrations of active particles, though possessing a great amount of energy, affect but little the average heat capacity and thermal conductivity of the mixture, but they may considerably influence the enthalpy flux. Indeed, in the course of calculation of enthalpy fluxes the temperature values measured by a thermocouple correspond to the real ones. But, measurement of the great amounts of recombination energy of free 
radicals dissipating in the sampling system does not seem to be possible. Then, if allowed for the free radical contribution to the concentrations of stable species (we have to do so because of the absence of data on radical concentrations), it would result in the reduction of the calculated heat content of the reacting mixture to its true value in the flame. Consequently, the presence of radicals in the flame can be detected by the seeming deviation from the law of conservation of energy. Calculations of the enthalpy flux in the propane-air flames inhibited by TF [26], showed smaller value of the deviation from the energy conservation law, which apparently corresponds to the reduction of the radicals concentration in the flames in the course of the burning inhibition.

TF molecules at low temperatures are consumed in the preflame zone, apparently, mostly in reactions with $\mathrm{H}$ atoms. Taking into account the previously determinated rate constant of the TF reaction with $H$ [5] the authors have calculated the concentration profiles of $\mathrm{H}$ atoms in the propane-air flame [20]. Concentration of $\mathrm{H}$ atoms at the inner boundary of the luminous zone is $1 \times 10^{17} \mathrm{~cm}^{-3}$, which agrees well with the measurements by the ESR-technique (Fig.31). Attention should be paid to the existence of a plateau on the plot over a range $z=-0.9 \mathrm{~mm}$. Its occurrence may be explained by the existence of an additional source of $\mathrm{H}$ atoms in the preflame zone due to the low temperature branching (400-500K).

Intramolecular quadratic annihilation as a possible source of low temperature branching

As the beginning of fuel consumption in the investigated flames was observed at a considerable distance from the luminous zone already at the room temperature, one of the main ways of radical formation in cold combustible mixture can be a reaction of hydrocarbons with $\mathrm{H}$ atoms diffusing upstream from the hot zone of the flame:

$$
\mathrm{H}+\mathrm{RH}=\mathrm{H}_{2}+\mathrm{R}
$$

This assumption is justified by the fact that $H$ atoms in comparison with other active particles in hydrocarbon flames are known to have the greatest diffusion coefficient. In this respect only $O$ atoms in lean flames can compete with $\mathrm{H}$ atoms when the 


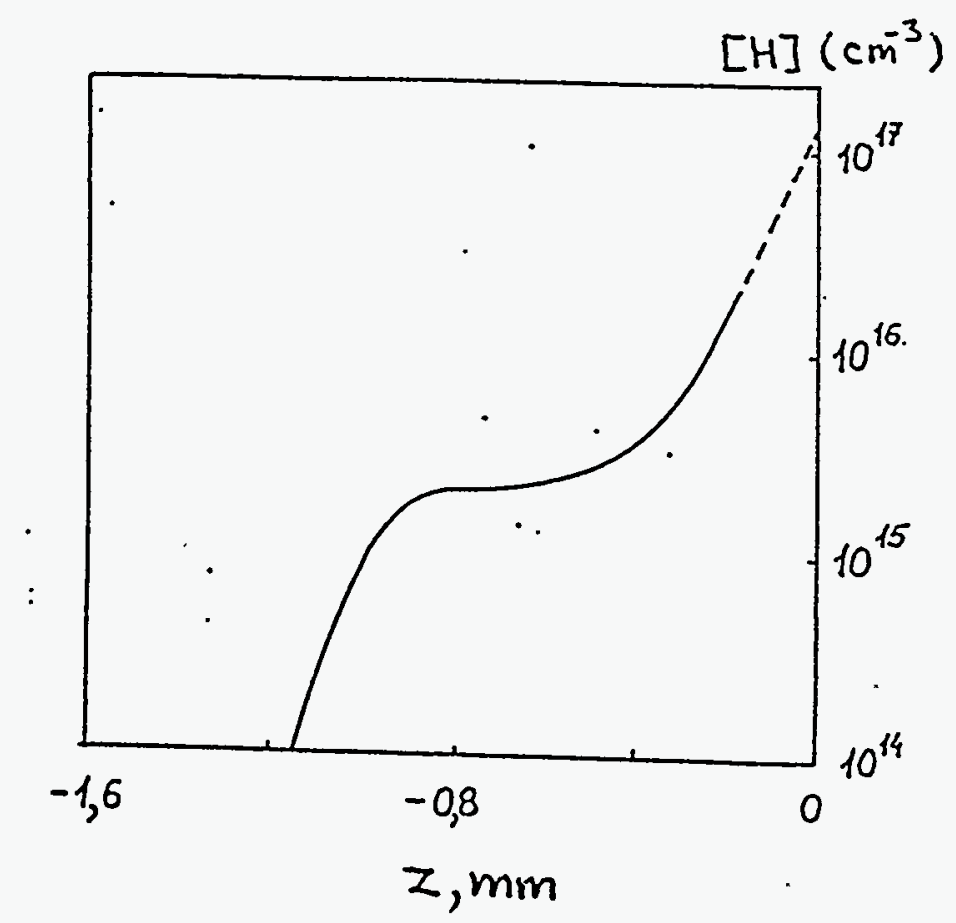

Fig.31. H atoms concentration profiles in inhibited by $\mathrm{C}_{2} \mathrm{~F}_{4} \mathrm{Br}_{2}$ propane-air flame (4.5\% $\mathrm{C}_{3} \mathrm{H}_{8} ; 94.3 \%$ air; $1.2 \% \mathrm{C}_{2} \mathrm{~F}_{4} \mathrm{Br}_{2}$ ). 
concentration of the former in the hot zone exceeds the concentration of the latter.

The standard branching reaction:

$$
\mathrm{H}+\mathrm{O}_{2}=\mathrm{OH}+\mathrm{O}
$$

at high pressure and low temperatures is far less important than:

$$
\mathrm{H}+\mathrm{O}_{2}+\mathrm{M}=\mathrm{HO}_{2}+\mathrm{M}
$$

in accordance with. the recent review of chemical kinetics of combustion processes [27]. Under these condition $\mathrm{HO}_{2}$ radicals react mostly with $\mathrm{H}$ :

$$
\mathrm{HO}_{2}+\mathrm{H}=2 \mathrm{OH}
$$

Then hydrocarbon $\mathrm{RH}$ can react with $\mathrm{OH}$ via reaction with a greater rate constant than that of (1):

$$
\mathrm{RH}+\mathrm{OH}=\mathrm{H}_{2} \mathrm{O}+\mathrm{R}
$$

Reaction (4) can proceed in other ways:

$$
\begin{aligned}
& \mathrm{HO}_{2}+\mathrm{H}=\mathrm{H}_{2} \mathrm{O}+\mathrm{O} \\
& \mathrm{HO}_{2}+\mathrm{H}=\mathrm{H}_{2}+\mathrm{O}_{2}
\end{aligned}
$$

Considering also reaction:

$$
\mathrm{RH}+\mathrm{O}=\mathrm{OH}+\mathrm{R}
$$

and ignoring other routes of $\mathrm{HO}_{2}, \mathrm{O}$ and $\mathrm{OH}$ disappearance because of their far less rate, as a quasi-stationary approximation we find:

$$
\left[\mathrm{HO}_{2}\right]=\frac{\mathrm{k}_{3}}{\mathrm{k}_{4}+\mathrm{k}_{6}+\mathrm{k}_{7}}\left[\mathrm{O}_{2}\right][\mathrm{M}],
$$




$$
\begin{aligned}
& {[\mathrm{O}]=} \frac{[\mathrm{H}]\left[\mathrm{O}_{2}\right]}{k_{8}[\mathrm{RH}]}\left(\mathrm{k}_{2}+\frac{\mathrm{k}_{3} \mathrm{k}_{6}}{\mathrm{k}_{4}+\mathrm{k}_{6}+\mathrm{k}_{7}}[\mathrm{M}]\right), \\
& {[\mathrm{OH}]=\frac{[\mathrm{H}]\left[\mathrm{O}_{2}\right]}{\mathrm{k}_{5}[\mathrm{RH}]}\left(2 \mathrm{k}_{2}+\mathrm{k}_{3}[\mathrm{M}] \frac{2 \mathrm{k}_{4}+\mathrm{k}_{6}}{\mathrm{k}_{4}+\mathrm{k}_{6}+\mathrm{k}_{7}}\right) }
\end{aligned}
$$

The ratio of hydrocarbon consumption rates via reactions (1) and (5) is:

$$
\frac{\dot{w}_{1}}{w_{5}}=\frac{k_{1}[\mathrm{H}][\mathrm{RH}]}{k_{5}[\mathrm{OH}][\mathrm{RH}]}=\frac{k_{1}[\mathrm{RH}]}{\left[\mathrm{O}_{2}\right]\left(2 \mathrm{k}_{2}+\mathrm{k}_{3}[\mathrm{M}]-\frac{2 \mathrm{k}_{4}+\mathrm{k}_{6}}{\mathrm{k}_{4}+\mathrm{k}_{6}+\mathrm{k}_{7}}\right)}
$$

Using the following values of rate constants [27]:

$$
\begin{aligned}
& k_{1}=10^{13.01} \exp (-3130 / \mathrm{T}) \mathrm{cm}^{3} \mathrm{~mole}^{-1} \mathrm{c}^{-1} \\
& \mathrm{k}_{2}=10^{14.19} \exp (-8420 / \mathrm{T}) \mathrm{cm}^{3} \mathrm{~mole}^{-1} \mathrm{c}^{-1} \\
& \mathrm{k}_{3}=10^{14.71} \mathrm{~cm}^{6} \mathrm{~mole}^{-2} \mathrm{c}^{-1}
\end{aligned}
$$

and the ratio $k_{4}: k_{6}: k_{7}=1: 12: 10$ [28], and taking concentration for the propane-air flame [17] we have found for $T=302 \mathrm{~K}$ :

$\mathrm{w}_{1} / \mathrm{w}_{5}=0,0064$.

If taken into account new values $k_{4}, k_{5}$ and $k_{7}$ corresponds to [29] lead to the increase in $\left(2 k_{4}+k_{6}\right) /\left(k_{4}+k_{6}+k_{7}\right)$ but not more than 2-3 times. This causes the same times decrease in the ratio $w_{1} / w_{5}$ which doesn't anyhow change the essence of our conclusion.

- The contribution of branching reaction becomes considerable at temperatures higher than 700K. OH concentration at the cold boundary of the flame front is determined by $\mathrm{H}$ concentration. Therefore, though hydrocarbons are mainly consumed via reaction (5) with $\mathrm{OH}$, the primary cause of chain initiation in the preflame zone is the diffusion of $H$ atoms to this place from the high temperature flame zone.

In connection with this the results of the contact (microprobing method) and non-contact (laser-induced fluorescence - IIF) analysis techniques can be compared. Fig.32 gives the 
results of the oH radicals distribution measurement by LIF in the methane flame front [30]. The shape of the concentration profile is seen to reproduce the $\mathrm{H}$ concentration profile.

To describe the processes in the preflame zone it is necessary to identify the possible source of $H$ atoms at temperatures of 350-450K. This source is probably connected with the following reaction of alkyl radicals. The mechanism of their thermal decomposition proposed by Warnatz $[29,31]$ with the elimination of alkenes is hot fast enough for the mentioned temperature range. Among the rapid low temperature reactions the disproportionation reactions are possible, for example:

$$
\mathrm{C}_{3} \mathrm{H}_{7}+\mathrm{H}-\rightarrow \mathrm{CH}_{3}+\mathrm{C}_{2} \mathrm{H}_{5}
$$

or reaction of peroxide formation:

$$
\mathrm{R}+\mathrm{O}_{2} \rightarrow \mathrm{RO}_{2} \rightarrow \mathrm{R}^{\prime}-\mathrm{CH}=\mathrm{CH}_{2}+\mathrm{HO}_{2}
$$

The requirements to the conversion mechanism scheme of the peroxide radical are rather simple. Judging by the distribution of the $H$ and of atoms, it is necessary to take into account the possible existence of the low temperature source of radicals $\mathrm{OH}$, $\mathrm{HO}_{2}$, etc. The scheme with the low-temperature branching is supposed to contain elementary reactions of monomolecular decomposition with intensive chain branching. It is clear that the repeatedness of these act is small, as such an "delayed" branching competes with a number of alternative channels, in particular conversion of $\mathrm{RO}_{2}$ according to (10).

The approximate evaluation [5] shows that the rates of these reactions are roughly equal, the rate of reaction (10) somewhat prevailing. The detection in the preflame zone of both peroxy radicals [12] and peroxy compounds [9] speaks in favour of this suggestion. Reaction (9) propagating the chain provides only the breaking of the initial molecule, but reaction (10) due to the intensive diffusion flux of $H$ atoms may lead, in contrast, to the formation of peroxy biradicals, as described below.

Using an isomerization scheme of the peroxide radical $[32,33]$ and applying a mechanism scheme of the intramolecular square annihilation [5], one can imagine the following conversion hypothetical scheme can be suggested at low temperatures: 


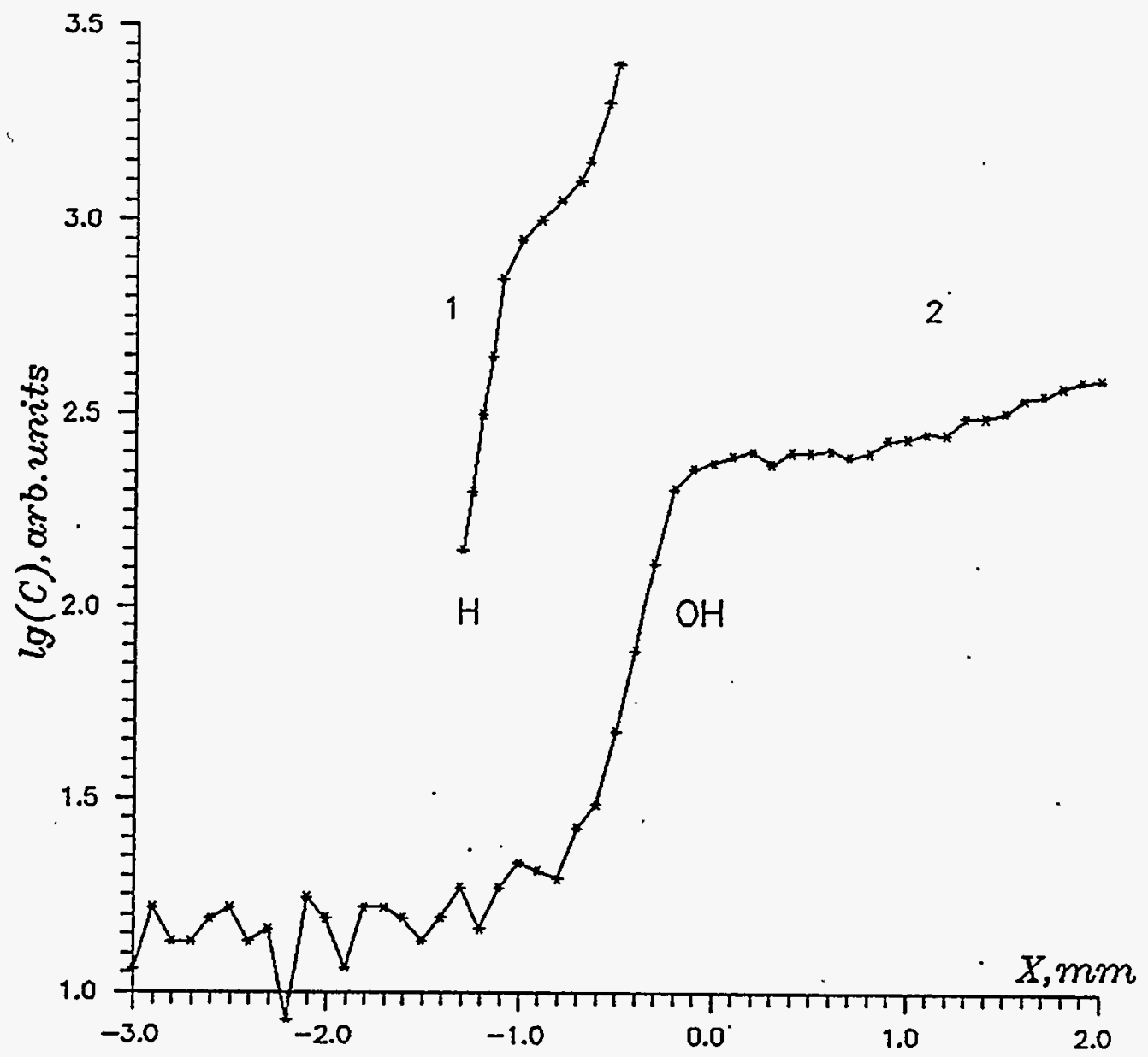

Fig.32. Concentration profiles in methane Bunsen flame. 1 - H-atom profile; 2 - OH-radical profile. 


$$
\begin{aligned}
& \mathrm{CH}_{3} \mathrm{CH}_{2} \mathrm{CH}_{2} \dot{\mathrm{O}}_{2} \rightarrow \dot{\mathrm{CH}}_{2} \mathrm{CH}_{2} \mathrm{CH}_{2} \mathrm{OOH} \\
& \dot{\mathrm{C}} \mathrm{CH}_{2} \mathrm{CH}_{2} \mathrm{CH}_{2} \mathrm{OOH} \rightarrow \dot{\mathrm{CH}}_{2} \mathrm{CH}_{2} \mathrm{CH}_{2} \dot{\mathrm{O}}+\dot{\mathrm{OH}} \\
& \stackrel{\mathrm{CH}_{2}}{\stackrel{\circ}{\mathrm{O}_{\mathrm{CH}_{2}}}}{ }^{\mathrm{CH}_{2}} \rightarrow\left[\mathrm{CH}_{1_{\mathrm{CH}_{2}}^{\prime}}^{\prime}{ }^{\mathrm{O}} \mathrm{CH}_{2}\right]^{*} \rightarrow \dot{\mathrm{CH}}_{2}-\mathrm{O}-\mathrm{CH}_{2} \dot{\mathrm{CH}}_{2} \\
& \mathrm{CH}_{2}-\mathrm{O}-\mathrm{CH}_{2} \mathrm{CH}_{2}+2 \mathrm{O}_{2} \rightarrow \mathrm{O}_{2} \mathrm{CH}_{2}-\mathrm{O}-\mathrm{CH}_{2}-\mathrm{CH}_{2} \mathrm{O}_{2} \\
& \dot{\mathrm{O}}_{2} \mathrm{CH}_{2}-\mathrm{O}-\mathrm{CH}_{2} \mathrm{CH}_{2} \dot{\mathrm{O}}_{2} \rightarrow \mathrm{O}_{2}+\dot{\mathrm{OCH}}_{2}-\mathrm{O}-\mathrm{CH}_{2} \mathrm{CH}_{2} \dot{\mathrm{o}}
\end{aligned}
$$

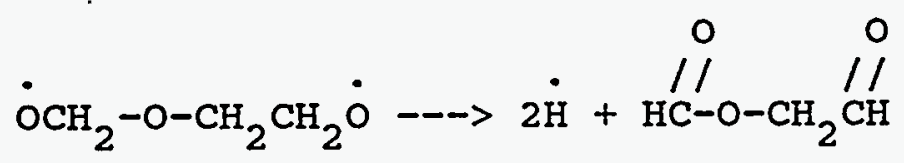

$$
\begin{aligned}
& \mathrm{HC}_{\mathrm{HC}}^{\mathrm{O}-\mathrm{CH}_{2}} \stackrel{\mathrm{CH}}{\mathrm{CH}} \rightarrow \dot{\mathrm{H}}+\mathrm{CO}_{2}+\ddot{\mathrm{CH}}_{2}+\dot{\mathrm{HCO}} ; \ddot{\mathrm{CH}}_{2}+\mathrm{O}_{2} \rightarrow \mathrm{CO}_{2}+2 \dot{\mathrm{H}}
\end{aligned}
$$

The total of the reactions given above does not pretend to be complete, but it seems to meet the demands of the low-temperature reaction scheme.

Among the alternatives of the $\mathrm{RO}_{2}$ conversion, there shouldn't to be excluded earlier [5] discussed attacks with $\mathrm{H}$ and $\mathrm{OH}$ atoms:

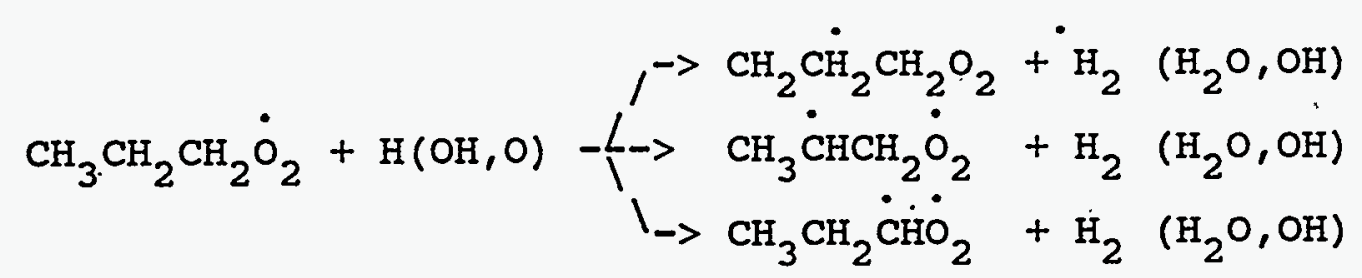

Peroxy biradicals $\mathrm{RO}_{2}$ formed (the formation of alkoxy biradicals $\ddot{R O}$ is also probable) can react with $\mathrm{O}_{2}$ forming other labile biradicals:

$$
\begin{aligned}
& \ddot{\mathrm{RO}}_{2}+\mathrm{O}_{2}-\rightarrow \ddot{\mathrm{RO}}_{4} \\
& \ddot{\mathrm{RO}}_{2}+\mathrm{o}_{2} \rightarrow \ddot{\mathrm{RO}}_{3}+\ddot{\circ}
\end{aligned}
$$

The decomposition or isomerization of these particles seems to be nonactivated and results in branching with simultaneous $\mathrm{CO}_{\text {, }}$ 
evolution. Nonactivated isomerization of peroxy and alkoxy biradicals is also possible by the way of intramolecular quadratic annihilation. Very unstable particles formed in such a process should be considered rather as an activated complex with highly populated upper vibration levels. Decomposition of the complex can lead to branching and simultaneous breaking of original fuel molecules, and that is the main feature of the preflame zone. If we assume that as a result of isomerization the biradical energy increases by the magnitude of $\mathrm{c}-\mathrm{O}$ bond energy, then a store of energy in the activated complex will amount to 530-580 $\mathrm{kJ} / \mathrm{mole}$ and its decomposition will occur with the scission of $\mathrm{C}-\mathrm{C}$ and $\mathrm{O}-\mathrm{O}$ bonds, for example:

$$
\begin{aligned}
& {\left[\stackrel{\mathrm{O}-\mathrm{O} \backslash}{\mathrm{CH}_{2} \mathrm{CH}_{2} \mathrm{CH}_{2}}\right]^{*} \rightarrow 2 \mathrm{CH}_{2} \mathrm{O}+\ddot{\mathrm{CH}}_{2}+Q} \\
& {\left[\stackrel{\mathrm{O}}{\mathrm{CH}_{3} \mathrm{CHCH}_{2}}\right]^{\mathrm{O}} \rightarrow \mathrm{CH}_{2} \mathrm{O}+\mathrm{CH}_{3} \mathrm{CHO}+Q}
\end{aligned}
$$

Exothermic effect $Q$ of such reactions is evaluated to be about $420 \mathrm{~kJ} / \mathrm{mole}$ and if most of this energy is concentrated on one of the decomposition products, energy branching is possible:

$$
\begin{aligned}
& \mathrm{CH}_{2} \mathrm{O}^{*}--\mathrm{C} \mathrm{CHO}+\dot{\mathrm{H}} \\
& \mathrm{CH}_{3} \mathrm{CHO}^{*} \rightarrow \mathrm{CH}_{3} \dot{\mathrm{CO}}+\dot{\mathrm{H}} \\
& \mathrm{CH}_{2} \mathrm{O}^{*}+\mathrm{M} \longrightarrow \rightarrow \mathrm{CH}_{2} \mathrm{O}+\mathrm{M}
\end{aligned}
$$

The reaction proposed by Warnatz [31] can also be a source of $H$ atoms.

$$
\ddot{\mathrm{CH}}_{2}+\mathrm{O}_{2} \rightarrow \mathrm{CO}_{2}+\dot{\mathrm{H}}+\dot{\mathrm{H}}
$$

There is a great number of conceivable variants of peroxy biradical conversions and they can account for the formation of all products in the flame. But at present the consideration of these variants in detail is useless, since not only the ways of conversion, but peroxy and alkoxy biradicals themselves have not been discovered experimentally. 
From all the above experimental material it follows that the mechanism of fuel oxidation under the conditions of low temperature reaction zone of the atmospheric pressure hydrocarbon flame front must meet the main requirements: 1)fuel conversion must take place in gas phase according to the scheme with minimum expenditure of heat and minimum heat release but with possible formation of final combustion product; 2) there must be branching acts within the preflame zone. At present among other possible mechanisms of oxidative cracking of fuel molecules in the preflame zone at low temperatures satisfying these requirements there is no alternative to the suggested hypothetical mechanism in which part of enthalpy of fuel and free radicals, diffusing into the initial mixture, is used to break down fuel molecules bonds.

It should also be noted that, in the presence of intensive diffusion flux of active particles from the hot zone, dehydrohenation processes are likely. to result in the formation of some polyradicals in case of long-chain hydrocarbons. In the case of the deficit of oxygen such polyradicals become a cause of soot particle nucleation. If oxygen is in excess, the formation of polyperoxy polyradicals is possible, the decomposition of the latter also seeming by taking place with branching.

In rich flames the maximum heat release rate is probably due to radical recombination reactions in the hot zone where their concentrations are supraequilibrium values. In this case recombination can result in the formation of particles with a rather high energy $\mathrm{CH}_{2}, \mathrm{C}_{2}, \mathrm{CH}, \mathrm{C}_{3} \mathrm{H}$ etc. Spatial separation of heat release rate maximum and fuel disappearance net rate maximum is obviously connected with the occurrence of branching reactions in the preflame zone prevailing over the recombination reactions in some steps of fuel conversion. A theoretical possibility of such a case was considered by Zel'dovich [3].

Having introduced in the kinetic scheme a highly branched reaction in which only recombination of active centers results in heat release, zel'dovich found that the zones of reaction and heat release were spatially separated especially in case of small recombination rates. The possible application of this result to hydrocarbon burning has been demonstrated in [5]. 


\section{Conclusion}

Thus, though the whole complex of the considered results demonstrates convincingly the existence of low temperature reaction zone in the premixed laminar atmospheric hydrocarbon flames of Bunsen type, a theory of such flames has not yet been practically developed. Considerable efforts can be required either in search of hypothetical peroxy and alkoxy polyradicals in the preflame zone because of their lability and small concentrations, or in search of alternative mechanisms of rapid conversion of fuel at low temperatures with chain branching.

However, the importance of such investigations, taking into account their practical significance in regulation of burning by inhibition and promotion, in regulation of combustion product compositions, in the usage of flames in chemical synthesis etc., can be worthy of any efforts. . 


\section{List of reference}

1. Zel'dovich, Ya.B., and Frank-Kamenetsky, D.A., Zhurnal Fizicheskoi Khimii, 12:100-105 (1938).

2. Zel'dovich, Ya.B., and Semenov N.N., Zhurnal Eksperimental'noi i Teoreticheskoi Fiziki, 10:1116-1136 (1940).

3. Zel'dovich, Ya.B., Kinetika i Kataliz, 2:305-318 (1961).

4. Dubinin, V.V., Kolesnikov, B. Ya, Ksandopulo G.I. Fizika Goreniya i Veryva, 13:920-924. (1977).

5. Ksandopulo, G.I., Khimiya Plameni, Khimiya Press, Moscow, 1980, $256 \mathrm{p} \cdot \mathrm{p}$.

6. Fristrom, R.M., and Westenberg, A.A., Flame Structure, McGraw-Hill, New York, 1965, 424 p.p.

7. Collet, M.B., et al. Combust. and Flame. 1982. v.44. No.1-3. p.3-14.

8.Ksandopulo, G.I., Kolesnikov, B.Ya., and Odnorog, D.S., Fizika Goreniya i Vzryva, 10:841-847 (1974).

9.Ksandopylo G.I., Sagindykov, A.A., Kudaibergenov, S.E., and Mansurov, Z.A., Fizika Goreniya i Vzryva, 11:838-843 (1975). 10. Zenin, A.A., Zhurnal prikladnoi mekhaniki $i$ tekhnicheskoi fiziki.

11.Ksandopylo G.I., Kolesnikov B.Ya., Dubinin, V.V., and Odnorog, D.S., Fiziḳa Goreniya i Vzryva, 13:641-643 (1977).

12.Ksandopylo, G.I., and zubtsova, R.A., Fizika Goreniya i Vzryva, 19:21-23 (1983).

13.Manzhos,V.K., Kolesnikov B.Ya., Murzagaliev, A.K., and Ksandopylo G.I., Fizika Goreniya i Vzryva, 18:30-33 (1982).

14.Manzhos, V.K., Kolesnikov B.Ya., Ksandopylo, G.I., Khimicheskaya Fizika, 1:838-842 (1982).

15.Manzhos, V.K., Novikova S.P., Kolesnikov B.Ya., Ksandopylo, G.I., in Khimiya i Khimicheskaya Tekhnologiya (O.A. Songina, Ed.), KazGU Press, Alma-Ata, 1975, Vypusk 18, p.p 135-138.

16. Manzhos, V.K., Kolesnikov, B.Ya., Ksandopylo, G.I., Archivum Combustions. v.8. No.2. 1988. p.p.149-165.

17. Ksandopylo, G.I., Kolesnikov, B.Ya., and Odnorog, D.S., Doklady Akademii Nauk SSSR, 216:1098-1101 (1974).

18. Bozheeva, G.M. Flame front structure of laminar pentane flames. Ph.D. Thesis on Chemistry. Alma-Ata. 1989. 181p.

19. Kopylova, I.I. Methane flame front structure. Ph.D. Thesis on Chemistry. Alma-Ata. 1994. 120p.

20.. Ksandopylo, G.I., Kolesnikov B.Ya., and Odnorog, D.S., Fizika 
Goreniya i Vzryva, 11:60-67 (1975).

21. KsandopyIo, G.I., Kolesnikov B.Ya., and Odnorog, D.S., Fizika Goreniya i Vzryva, 11:131-134 (1975).

22. Gogol', L.A., Kononenko, K.M., Odnorog, D.S., Kolesnikov, B.Ya., and Ksandopulo G.I., in Ingibirovanie Tzepnykh Gazovykh Reaktsii (G.I. Ksandopulo, and V.I. Vedeneev, Eds.),

KazGU Press, Alma-Ata, 1971, p.p 205-213.

23. Manzhos, V.K., Kolesnikov B.Ya., Kopylova, L.I., and Lagutkina, Z.V., React. Kinet. Catal. Lett., 19:161-165 (1982).

24. Manzhos, V.K., Kolesnikov B.Ya., Ksandopylo, G.I., Oxidation Communication, 4:393-401 (1983).

25. Dubinin, V.V., and Ksandopylo G.I., Fizika Goreniya i Vzryva, $14: 30-33(1978)$.

26. Ksandopylo, G.I., Kolesnikov, B.Ya., Dubinin, V.V., and Odnorog, D.S., Fizika Goreniya i Vzryva, 11:412-418 (1975).

27. Westbrook, C.K., and Dryer, F.I., Eighteenth Symposium (International) on Combustion, The combustion Institute, Pittsburgh, 1981, p.p. 749-767.

28. Dodonov, A.F., Lavrovskaya, G.K., and Tal'roze, V.I., Kinetika i Kataliz, 10:701-705 (1969).

29. Chemistry of combustion Engl. translat. (W.Gardiner Ed.) Moskva. Mir. $1988464 \mathrm{p}$.

30. Dyakov, I.V. OH radical distribution in the Bunsen hydrocarbon flames. Ph.D. Thesis on Chemistry. Alma-Ata. 1994. 110p.

31. Warnats, J., Eighteenth Symposium (International) on Combustion, The Combustion Institute, Pittsburgh, 1981, p.p. 369-384.

32. Bozzelli, J.W., Pitz, W.J. 25th Int. simp. on Combustion. Abstr. Simp. Pap. 1994. p.17.

33. Hughes, K.J., Halford-Maw, P.A., Iightfood, P.D., 24th Int. Simp. on Combustion. The Combustion Institute. Pittsburgh. 1992. p.p. 645-652. 
